\title{
Trade Openness and the Settlement of Domestic Disputes in the Shadow of the Future ${ }^{\dagger}$
}

\author{
Michelle R. Garfinkel \\ University of California, Irvine \\ Constantinos Syropoulos \\ Drexel University
}

Current Version: February 16, 2015

\begin{abstract}
We explore the severity of an ongoing dispute over a productive resource within a country that participates in world trade. In addition to arming, the contending groups in our setting choose either to engage in destructive conflict or to settle their dispute peacefully. Our central objective is to characterize the conditions under which the dispute might be resolved peacefully instead of violently. The analysis underscores the intuitive roles played by the destructiveness of open conflict and the salience of the future that have been identified in the previous literature, but it also provides some novel insights on how world prices and trade openness matter. Among other things, we find that, given conflict's destructive effects and time preferences, settlement is most likely to be supported as a stable equilibrium when the "traditional" gains from trade are largest. However, there also exist circumstances under which increased trade openness can induce destructive conflict.
\end{abstract}

JEL Classification: D30, D74, F10, F60.

Keywords: Trade openness, domestic disputes, resource insecurity, peaceful settlement, open conflict, shadow of the future.

\footnotetext{
${ }^{\dagger}$ We thank, without implicating, Elias Dinopoulos, Stergios Skaperdas and Tom Zylkin who provided invaluable suggestions on earlier drafts of this paper.
} 


\section{Introduction}

Scholars of international relations have long debated the effects of globalization on conflict. The classical liberal perspective emphasizes the opportunity costs of interstate conflict, arguing that countries will be less likely to go to a war with others when that means sacrificing the potential benefits of trade between them (e.g., Polachek, 1980). ${ }^{1}$ By contrast, the realist perspective, emphasizing the anarchic nature of interactions between sovereign states, argues that international trade augments incomes and military strength so as to possibly amplify conflict (e.g., Waltz, 1979; Gowa, 1995). While the existing empirical evidence has not resolved this debate, ${ }^{2}$ the increased incidence of intrastate wars in the post WWII period suggests that more insight could be obtained by focusing on this type of conflict. ${ }^{3}$

This paper analyzes the severity of a dispute over a contested resource within a small nation that trades in world markets, when that dispute is ongoing. Our central objective is to characterize the conditions under which the dispute might be resolved peacefully instead of violently. The analysis builds on the static model of domestic conflict within a small country and international trade presented in Garfinkel et al. (2008). ${ }^{4}$ It views conflict as resulting from weak institutions of property rights and enforcement. Disputes between groups over the nation's resources - for example, oil and minerals - induce those groups to arm so as to take control of a larger share. ${ }^{5}$ But, departing from Garfinkel et al. (2008), the analysis distinguishes between mobilization of resources to arm and the deployment of those arms in open conflict, along the lines of Garfinkel and Skaperdas (2000) and McBride and Skaperdas $(2007,2014){ }^{6}$

More specifically, once the contending groups have made their arming choices, they choose how to resolve their dispute. One option involves violent or open conflict, modeled as a winner-take-all contest, with some fraction of the nation's remaining resources (after arms have been produced) being destroyed as a result. ${ }^{7}$ The other option, supported by the arms produced and the threat of open conflict, involves a peaceful division of the contested

\footnotetext{
${ }^{1}$ For an overview, also see Gilpin (1987, pp. 26-31).

${ }^{2}$ See, for example, Barbieri and Schneider (1999).

${ }^{3}$ Blattman and Miguel (2010) provide a comprehensive survey of the causes and consequences of civil wars.

${ }^{4}$ Our focus on a small country means that product prices are given exogenously. See Skaperdas and Syropoulos (2001) who use a similar static framework, generalized in Garfinkel et al. (2015), to study globalization and interstate conflict. Dal Bó and Dal Bó (2011) study international trade and domestic conflict in a different, though similarly static, setting.

${ }^{5}$ See Klare (2001) for an overview, including many examples of how disputes over resources can and have led to conflict, both within and between countries. This sort of conflict is distinct from insecurity in trade where weak institutions of governance can undermine the fulfillment of implicit or implicit contracts between trading partners (e.g., Dixit, 2004 and 2015) or can induce parties to take protective measures against cheating or theft by other parties (e.g., Anderson and Marcouiller, 2005) that are sufficiently costly to make trade undesirable.

${ }^{6}$ See Fearon (1995), Skaperdas and Syropoulos (1996), and Powell (2006) for similar approaches.

${ }^{7}$ The destructive effects of civil wars (e.g., lost lives, damaged property, and so on) have been significant (see Collier et. al. 2003).
} 
resource. Given whatever arms they choose, the contending groups always have a shortrun incentive to negotiate a peaceful settlement, for that option allows them to divide the contested resource without having to deploy arms and incur destruction. However, when the groups take a longer-run perspective, settlement need not emerge as a subgame perfect, Nash equilibrium. The reason is that settlement in the current period concerns the division of resources only in that period; absent the possibility for the groups to commit to a division of the contested resource in the future, settlement requires some diversion of resources away from the production of goods for consumption in the future as well as in the current period. Open conflict in the current period, by contrast, gives the victor a strategic advantage in future conflict, so that fighting today reduces future arming costs relative to those under settlement. In fact, open conflict is always a subgame perfect, Nash equilibrium. Moreover, depending on world prices, trade costs, the shadow of the future, and the degree of conflict's destructiveness, open conflict could Pareto dominate peaceful settlement. ${ }^{8}$

Our analysis characterizes the conditions that ensure settlement can also arise as an equilibrium. Along the lines of the existing theoretical literature, our findings underscore the intuitive roles played by the destructiveness of conflict and the salience of the future (or the "shadow of the future"), with the former increasing the relative appeal of settlement and the latter reducing it. For example, peaceful settlement is more likely to be Pareto dominant, given the world price and trade costs, when conflict's destructive effects are sufficiently large and the shadow of the future small. ${ }^{9}$ Nonetheless, the Pareto dominance of peaceful settlement over open conflict cannot ensure its emergence as another subgame perfect, Nash equilibrium. An additional requirement is that settlement be immune to unilateral deviations in arming and in the choice of peaceful settlement. Our analysis shows that settlement is more likely to arise as a stable equilibrium under conditions that are generally stronger and considerably more nuanced than those that ensure its Pareto dominance.

Moving beyond the existing theoretical literature, we also demonstrate how world prices and trade openness or, more generally, globalization (captured, for example, by reductions in trade costs) matter. First, they matter for payoffs given the method by which the contending groups resolve their dispute. Here the influence is twofold: the direct, terms-of-trade effect and the indirect effect that works through arming incentives. As expected, regardless of whether the groups anticipate conflict or settlement or even when they consider a unilateral deviation from settlement, an increase in the world price of the good that employs the contested resource intensively increases the value of the contested resource relative to the cost of producing arms, and thus amplifies arming incentives. Provided that the resource

\footnotetext{
${ }^{8}$ In such cases, open conflict is a "strong perfect equilibrium" or, equivalently (in the two player setting we consider), a "perfectly coalition-proof" equilibrium (Bernheim et al., 1987).

${ }^{9}$ See McBride et al. (2014), who obtain a similar welfare implication in the context of litigation. This result would also seem to follow from the analyses of McBride and Skaperdas (2007, 2014).
} 
constraint in the production of arms is not binding, the wasteful diversion of resources into arming expands with increases in that world price. This expansion occurs regardless of the pattern of trade. Hence, given the method by which the groups resolve their dispute (i.e., settlement or conflict), the introduction of trade, improvements in the country's terms of trade, and trade liberalization could be dominated in welfare by autarky for an intermediate range of prices that make the country a net exporter of the good produced intensively with the contested resource. ${ }^{10}$ However, because the magnitude of the wasteful diversion of resources into arming depends on whether groups settle or fight, the pattern of trade itself depends on how groups resolve their dispute. As such, a terms-of-trade improvement under, say, open conflict could be a terms-of-trade deterioration under peaceful settlement.

Second, changes in world prices and trade openness affect the groups' incentives for coalitional and/or unilateral deviations from settlement and thus can influence the incidence of destructive conflict and/or peaceful settlement as well as welfare. Therefore, depending on the rate of destruction and time preferences, an improvement in an economy's terms of trade could bring about a switch from settlement to open conflict or conversely, with its attendant consequences for welfare. We find, for example, that as long as the groups value the future, trade openness can induce destructive conflict; however, it is also possible that trade openness helps to support peaceful settlement as a stable equilibrium, especially when world prices differ substantially from the ones that would arise under autarky (i.e., precisely when we expect the "traditional" gains from trade to be highest). As such, we find some theoretical support for the two competing views in the international relations literature mentioned earlier. ${ }^{11}$ More generally, our results reveal a complex relation between trade openness and the risk of open conflict, depending on conflict's destructiveness and the shadow of the future.

In what follows, the next section presents the basic model and derives some preliminary results that allow us in Section 3 to study arming incentives under conflict and those under settlement. Section 4 characterizes the welfare implications of these two modes of conflict resolution, whereas Section 5 studies the conditions under which settlement is and is not a stable equilibrium outcome. Section 6 examines the influence of trade openness on equilibrium outcomes and payoffs. Finally, Section 7 offers some concluding remarks.

\footnotetext{
${ }^{10}$ See Garfinkel et al. (2008) for a similar finding under non-destructive conflict.

${ }^{11}$ These findings are also consistent with the empirical evidence presented in Martin et al. (2008), but the logic underlying our findings differs considerably from their interpretation of the evidence. Specifically, their empirical analysis is motivated by two offsetting effects of trade openness on the risk of internal conflict: (i) a deterrence effect that arises as internal conflict disrupts external trade and (ii) an insurance effect that arises as internal conflict disrupts internal trade. Neither consideration is relevant in our analysis, since we do not explicitly consider the potentially disruptive effects of conflict on trade.
} 


\section{Resolving a Domestic Dispute}

The analysis is based on the model of domestic conflict and trade presented in Garfinkel et al. (2008), with some simplifications, but extended over an indefinite time horizon. Consider a country populated by 2 identical groups, indexed by $i=1,2$. In each period, the country is endowed with two types of resources, land and labor, which can be converted on a one-to-one basis into respectively oil and butter, two goods for final consumption. Each group $i$ holds $L$ units of secure labor, which can also be used to produce guns (or arms), similarly on a one-to-one basis. Let $G^{i}$ denote group $i$ 's level of arming or guns production. Then, $L-G^{i}$ $(\geq 0)$ units of labor will potentially be available for the production of butter. ${ }^{12}$

The two final consumption goods, oil and butter, are produced under perfectly competitive conditions. They can be traded domestically as well as internationally. ${ }^{13}$ Let $O^{i}$ and $B^{i}$ denote group $i$ 's consumption of oil and butter respectively. Each group $i$ 's preferences take the Cobb-Douglas form,

$$
w\left(O^{i}, B^{i}\right)=\left(O^{i}\right)^{\alpha}\left(B^{i}\right)^{\beta}
$$

for $i=1,2$, where $\alpha \in(0,1)$ and $\alpha+\beta=1$. $^{14}$

While the two groups hold secure claims on the goods they produce and on those they exchange, as well as their respective labor endowments, they contest the country's endowment of land or territory, $\bar{T} .{ }^{15}$ Each group would like to take control of the contested territory, particularly for its oil. But, due to imperfect institutions of governance and enforcement, claims to this territory can be resolved only in one of two ways: through open conflict (war) or through "peaceful" settlement under the threat of open conflict (armed peace).

In the case of open conflict, guns determine each group $i$ 's probability of winning the dispute over $\bar{T}, q^{i}=q\left(G^{i}, G^{j}\right)$ for $i=1,2$ and $j \neq i$. Let $\bar{G}=G^{1}+G^{2}$ denote the aggregate quantity of guns chosen in the first stage of the current period. Then the probabilities are

\footnotetext{
${ }^{12}$ What we call "labor" can be more generally thought of as any secure resource held by the groups to produce/finance arms. As will be become evident below, the constraint that $L-G^{i} \geq 0$ plays an important role in determining equilibrium payoffs.

${ }^{13}$ The assumption that goods can be traded domestically is not essential here, since there is trade with the rest of the world. The analysis could be extended to capture the insurance effect of trade openness considered by Martin et al. (2008), by supposing that internal conflict disrupts internal trade, and then compare the incentives for groups to settle peacefully under autarky with those under trade. We expect the conditions for peaceful settlement to be a possible stable equilibrium would be weaker under trade. As noted below, we could also extend the analysis to consider the possible disruptive effects of internal conflict on external trade and thus capture the opportunity cost of conflict that has been emphasized by the classical liberal view and is also featured in Martin et al. (2008).

${ }^{14}$ Note that these preferences imply risk neutrality, which helps simplify matters as noted below.

${ }^{15}$ The analysis could be modified to suppose that only some fraction of the nation's territory, say $\tau \in(0,1]$, is insecure, and that each group holds an equal share $\frac{1}{2}(1-\tau)$ securely. Assuming $\tau=1$ simplifies the analysis without changing the results qualitatively.
} 
specified as follows:

$$
q^{i} \equiv q\left(G^{i}, G^{j}\right)= \begin{cases}G^{i} / \bar{G} & \text { if } \bar{G}>0 \\ 1 / 2 & \text { otherwise }\end{cases}
$$

for $i=1,2$ and $j \neq i$. This specification implies that group $i$ 's probability of winning is increasing in its own arming choice, $q_{G^{i}}^{i}>0$, and decreasing in the arming choice by the other group, $q_{G^{j}}^{i}<0, j \neq i$. Furthermore, it is symmetric so that when $G^{i}=G^{j}=G \geq 0$, $q^{i}=q^{j}=\frac{1}{2} \cdot{ }^{16}$ In the case that the two groups fight, some fraction denoted by $1-\phi \in[0,1)$ of the country's current-period land endowment and its labor endowment (net of what labor has been used to produce guns) is destroyed. ${ }^{17}$ However, this destruction is temporary; the nation's resource endowments of land and labor return to their pre-conflict levels in all future periods. ${ }^{18}$ Moreover, fighting today can bring with it future benefits, by virtue of its giving the winner a strategic advantage in future conflict. To highlight this effect, we assume that the winner of a conflict in the current period gains not only all of the contested land net of destruction in that period $(\phi \bar{T})$, but also all of the nation's land $(\bar{T})$ in each future period, without having to produce any additional guns. ${ }^{19}$

By contrast, when the two groups settle their differences peacefully, the land is divided according to a "split-the-surplus rule." We denote this rule, which is derived below, by $s^{i}$ for $i=1,2$ where $s^{j}=1-s^{i}$. As will become evident, this rule, like the probability of winning $q^{i}$, depends on the guns held by each group. However, in the case of settlement, there is no

\footnotetext{
${ }^{16}$ See Tullock (1980) who first introduced this functional form, often referred to as the "contest success function" (CSF). Also see Skaperdas (1996) who axiomatizes a general class of such functions, $q\left(G^{i}, G^{j}\right)=$ $f\left(G^{i}\right) / \sum_{j=1}^{2} f\left(G^{j}\right)$, assuming only that $f(\cdot)$ is a non-negative, increasing function. Finally, see Hirshleifer (1989), who explores the properties of two important functional forms of this class, including the "ratio success function," where $f(G)=G^{m}$ with $m>0$. Note that the results to follow would remain qualitatively unchanged under this more general specification with $m \in(0,1]$. But, to maintain clarity, we focus in on the specification in (2) where $m=1$.

${ }^{17}$ As will become evident shortly, assuming that conflict destroys equal proportions of land and residual labor endowments conveniently implies that the autarkic price is independent of the rate of destruction and whether the groups fight outright or settle their dispute (see equation (7) below). This simplifies the analysis, but does not alter the main insights.

${ }^{18}$ Another interpretation of $1-\phi \in[0,1)$, one that would be more consistent with the assumed temporary nature of conflict's destruction, is that the outbreak of conflict disrupts the productive process, making land and labor less effective in yielding respectively oil and butter. In any case, while assuming that open conflict's destructive effects are temporary tilts the balance of our analysis in favor of conflict, this assumption could easily be relaxed. In fact, as noted below, assuming instead that conflict's destruction in permanent simplifies the analysis considerably, while making some of our central results stronger.

${ }^{19}$ The assumption that the victor takes control of all of the nation's land forever is not innocuous. Indeed, nothing in our model specification prevents the loser of the contest in the current period from initiating conflict in future periods; if this were possible, conflict could induce higher future resource costs, thereby wiping out the basis for conflict's potential appeal relative to settlement. What we have in mind here is that defeat in conflict undermines the loser's capacity, organization and possibly even its will to enter into conflict in the future. Put differently, one could view conflict as crippling the losing group's ability to fight in the future. An alternative assumption would be that the loser is simply eliminated. Although this more dramatic assumption could make conflict less appealing, we suspect that it would not change the analysis in a substantive way.
} 
destruction of resources. Nevertheless, the two groups find themselves in the same struggle over the nation's land resources once again in the following period.

The timing of actions in the first period is as follows:

Stage 1. Each group $i$ chooses its allocation of labor to arming, $G^{i}$, taking the other group's decision, $G^{j} j \neq i$, as given.

Stage 2. Given those arming choices $\left(G^{i}\right.$ for $\left.i=1,2\right)$, the groups enter into negotiations about how to divide the contested land.

(2.a) If both groups agree on a division, they share the contested land accordingly. Each group $i$ then produces $s^{i} \bar{T}$ units of oil and $\max \left[L-G^{i}, 0\right]$ units of butter.

(2.b) Otherwise, their negotiations end in conflict, with the winner taking the entire land endowment net of damages induced by the war, $\phi \bar{T}$, leaving no land for the other group. In addition, each group's labor endowment net of what had been absorbed into arming is partially destroyed, leaving only $\phi\left(L-G^{i}\right)$ units of labor for each group to produce butter in that first period.

Stage 3. Given the production of butter and oil by both groups, competitive trade takes place with the outside world, at prices that the groups treat as exogenous.

What happens beyond the first period depends on whether the two groups settled peacefully or fought in the first. In the case of peaceful settlement in the initial period, the three stages specified above are repeated in the next period. In the case of open conflict, the winner takes all of the contested land in the second period and every period after that, and no labor resources are allocated to arming after the initial period.

Analyzing the two alternative methods of "resolving" the conflict and their implications for equilibrium arming requires that we first derive the current-period payoffs given the groups' arming choices made in stage 1 and contingent on the outcome of their dispute in stage 2. These contingent payoffs are based on the indirect utility functions implied by (1). Denote group $i$ 's land holdings, contingent on what happens in stage 2 and given the arming choices in stage 1 , by $\widehat{T}^{k i}$, where $k=c$ when the groups engage in open conflict and $k=s$ when they settle. From our previous description, these quantities are given by

$$
\widehat{T}^{k i}= \begin{cases}\bar{T} \widehat{\theta}^{i} \phi & \text { if } k=c \\ \bar{T} s^{i} & \text { if } k=s,\end{cases}
$$

for $i=1,2$, where $\widehat{\theta}^{i}$ is an indicator variable, taking on the value of 1 in the case that group $i$ wins the open conflict and the value of 0 otherwise. Clearly, $\operatorname{Prob}\left(\widehat{\theta}^{i}=1\right)$ equals $q\left(G^{i}, G^{j}\right)$.

Now, normalize the price of butter to 1 , and let $p$ denote the internal or domestic relative price of oil measured in units of butter faced by the country. Assuming that trade costs 
are zero, that price equals the world price. More generally, in the presence of trade costs, that price could differ from the world price as discussed below. In any case, the production structure specified above implies further that the prices of both guns and labor equal 1.

We can then write group $i$ 's contingent one-period income or revenue function as

$$
\widehat{R}_{J}^{k i} \equiv R\left(p, \widehat{T}^{k i}, L-G^{i}\right)=\left\{\begin{array}{cc}
{\left[p \bar{T} \widehat{\theta}^{i}+L-G^{i}\right] \phi} & \text { if } k=c \\
p \bar{T} s^{i}+L-G^{i} & \text { if } k=s
\end{array}\right.
$$

for $i=1,2, j \neq i$. Abstracting from international transfers of income, group $i$ 's total expenditure on butter and oil must be equal to this measure of income. Then, its contingent current-period indirect utility function implied by (1) can be written as

$$
\widehat{w}^{k i} \equiv w\left(p, R\left(p, \widehat{T}^{k i}, L-G^{i}\right)\right)= \begin{cases}\mu(p)\left[p \bar{T} \widehat{\theta}^{i}+L-G^{i}\right] \phi & \text { if } k=c \\ \mu(p)\left[p \bar{T} s^{i}+L-G^{i}\right] & \text { if } k=s\end{cases}
$$

for $i=1,2 j \neq i$, where $\mu(p)=\beta^{\beta}(\alpha / p)^{\alpha}$ represents the groups' (common) marginal utility of income. Using Roy's identity, one can verify that group $i$ 's contingent current-period demand and supply functions for oil are respectively $\alpha \widehat{R}_{J}^{k i} / p$ and $\widehat{T}^{k i}$; therefore, its excess demand function for oil, given the realization of $\widehat{T}^{k i}$, is

$$
\widehat{M}^{k i}(p)=\frac{\alpha \widehat{R}_{J}^{k i}}{p}-\widehat{T}^{k i}
$$

for $k=c, s$ and $i=1,2$, which is positive if the group demands (imports of) oil in the world market and negative if the group supplies (exports of) oil.

Given the aggregate allocation of resources to arming by both groups $\left(\bar{G}=\sum_{i=1,2} G^{i}\right)$, the market-clearing price that would prevail in the country if it were closed off entirely to trade with the rest of the world, denoted by $p_{A}$, is that which solves $\sum_{i=1,2} \widehat{M}^{k i}\left(p_{A}\right)=0$. Using equations (3), (4) and (6) and letting $\bar{L} \equiv 2 L$ denote the aggregate quantity of labor in the country, one can verify the following:

$$
p_{A}=p_{A}(\bar{G})=\frac{\alpha}{\beta}\left[\frac{\bar{L}-\bar{G}}{\bar{T}}\right] \text {. }
$$

As this expression shows, $p_{A}$ does not depend on whether the two groups settle or fight, since conflict's destructive effects equally impact both land and labor net of that allocated to arming. Moreover, equation (7) shows that the autarkic price does not depend on the distribution of labor, land or even guns across groups. Instead, it depends only on aggregate quantities. Note especially that, when more of the country's aggregate labor endowment is allocated to arming $(\bar{G})$, the amount of butter produced domestically necessarily falls; hence, 
as equation (7) shows, $p_{A}$ depends negatively on $\bar{G} \cdot{ }^{20}$ For future reference, let $p_{A}^{n}$ denote the autarkic price when no guns are produced. From (7), $p_{A}^{n}=\frac{\alpha}{\beta} \bar{L} / \bar{T}$.

\section{Expected Payoffs and the Incentives to Arm}

With these preliminary results, we now derive the expected current and future discounted payoffs under open conflict and settlement given the arming choices made by the two groups in the first stage of the first period. With these payoff functions, we characterize the groups' arming incentives.

\subsection{Open Conflict}

Let $u^{i}$ denote group $i$ 's current-period expected payoff under conflict given the quantity of arms chosen by both groups. Since the current-period indirect utility function contingent on the outcome of the conflict, (5) for $k=c$, depends linearly on the group's contingent land and labor holdings, group $i$ 's expected current-period payoff under conflict, given the guns choices by both groups, can be written as a function of group $i$ 's expected land and labor holdings:

$$
u^{i}=u^{i}\left(G^{i}, G^{j} ; p\right)=\mu(p)\left[p \bar{T} q\left(G^{i}, G^{j}\right)+L-G^{i}\right] \phi
$$

for $i=1,2, j \neq i$.

Now let $U^{i}$ denote the group' $i$ 's expected lifetime payoff under conflict and $\delta \in[0,1)$ denote the groups' common discount factor. For convenience, we define $\Delta \equiv \delta /(1-\delta) \in[0, \infty)$ as the shadow of the future. Since the winner of the conflict takes control of all of the disputed land in each future period (i.e., $\bar{T}$ ) with no subsequent destruction and since no resources are devoted to the conflict in future periods regardless of who wins, we can write group $i$ 's expected lifetime payoff as a function of current guns and the current and future relative price of oil. To keep matters simple, we assume that the future relative price equals the current relative price. ${ }^{21}$ Thus, we have

$$
U^{i}\left(G^{i}, G^{j}\right)=u^{i}\left(G^{i}, G^{j} ; p\right)+\Delta\left[\mu(p)\left(p \bar{T} q\left(G^{i}, G^{j}\right)+L\right)\right]
$$

for $i=1,2, j \neq i$. The dependence of this payoff on the first-stage arming choices by both parties works through the conflict technology $q\left(G^{i}, G^{j}\right)$ that enters both the current-

\footnotetext{
${ }^{20}$ This property holds under more general production structures where both consumption goods and guns are produced with the two factor inputs, as long as guns production is sufficiently labor intensive relative to the country's labor-land endowment ratio (see the Supplementary Appendix of Garfinkel et al., 2008).

${ }^{21}$ One could extend the analysis to study how changes in the future price-due to, for example, an anticipated trade liberalization or anticipated advances in technology that reduce future trade costs - affect current firstand second-stage decisions.
} 
period expected payoff and the discounted future expected payoff. Recalling that $q_{G^{i}}^{i}>0$, a comparison of the expression above with (8) shows that a group's incentive to arm in this multi-period setting is greater than what it would be in a one-period game.

Turning to those incentives, differentiation of this expected payoff with respect to $G^{i}$, given the opponent's choice $G^{j}$ and the relative price of oil $p$, yields:

$$
\frac{\partial U^{i}}{\partial G^{i}}=\mu(p)\left[\left(p \bar{T} q_{G^{i}}^{i}-1\right) \phi+\Delta p \bar{T} q_{G^{i}}^{i}\right]
$$

for $i=1,2$. The first term in the square brackets represents the current marginal benefit (measured in units of butter) of arming, due to its impact on the probability of capturing the entire land resource after destruction in that period, net of the current resources diverted from the production of butter to the production of guns and net of the destruction that accompanies open conflict. The second-term represents the future marginal benefit (again measured in butter units) in terms of increasing the probability of securing the entire land resource in future periods.

As can easily be verified, the specification of the conflict technology in equation (2) implies that the amount of arming by both groups will be strictly positive. As such, the expression in (10) when evaluated at the optimizing choices of arms assuming conflict will be nonnegative. However, depending on $p$, the labor constraint in the production of arms could bind. Taking that possibility into account while noting that $q_{G^{i}}^{i}=G^{j} / \bar{G}^{2}$, one can show that, in a symmetric equilibrium under conflict, group $i$ 's arming choice is given by

$$
G^{i c}=G^{c}= \begin{cases}\frac{p \bar{T}}{4}\left[1+\frac{\Delta}{\phi}\right]=L \frac{p}{\pi^{c}} & \text { if } p \leq \pi^{c} \\ L & \text { otherwise }\end{cases}
$$

for $i=1,2$, where $\pi^{c} \equiv\left(\frac{\phi}{\phi+\Delta}\right) 2 \bar{L} / \bar{T}$ denotes the threshold value of the price above which the labor constraint in the production of arms binds. ${ }^{22}$ If this were a static, one-period game (or equivalently $\Delta=0$ ), the allocation to guns would be simply $G^{c}=p \bar{T} / 4$ for $p \leq 2 \bar{L} / \bar{T}$ and $L$ otherwise. The second term inside the square brackets in the first expression on the first line $(\Delta / \phi)$ reflects the added incentive to arm due to the possible benefit of capturing the disputed resource in the future, a benefit that is larger when $\Delta$ is larger. Thus, as the future becomes more salient, $G^{c}$ rises for $p<\pi^{c}$. This term also reflects the positive influence of conflict's destructive effects $(1-\phi)$ on arming incentives. This influence can be interpreted as resulting from the effect of destruction in the current period to effectively make the future

\footnotetext{
${ }^{22}$ The resource constraint embedded in equation (11), that $G^{c} \leq L$, is important as will become evident below. For now, note that, if this constraint binds, the winning group specializes in the first period in the production of oil, whereas the defeated group gets a zero payoff. We would not expect such specialization if preferences were increasing and strictly concave in income.
} 
more relatively more important (analogous to an increase in $\Delta$ ), and the increase in arming can then be seen as an attempt substitute intertemporally. Finally, observe that $G^{c}$ is also increasing in the relative price of oil $p$ for $p<\pi^{c}$.

Since this arming choice is identical across the two groups for any $p, q^{i}=q^{j}=\frac{1}{2}$. Thus, equilibrium expected payoffs under conflict are identical across groups, and can be written as:

$$
U \equiv U\left(G^{c}, G^{c}\right)=\mu(p)\left[\phi\left(L-G^{c}+\frac{1}{2} p \bar{T}\right)+\Delta\left(L+\frac{1}{2} p \bar{T}\right)\right]
$$

for each $i=1,2$ and all $p$, where $G^{c}$ is given in equation (11). We return to characterize this function more fully as it depends on the key parameters $(p, \phi$ and $\Delta)$, after deriving the analogous solutions under peaceful settlement.

\subsection{Settlement}

Let $v^{i}$ denote group $i$ 's current-period payoff under settlement given the quantity of arms chosen by both groups. From (5) for $k=s$, we have

$$
v^{i}=v^{i}\left(G^{i}, G^{j} ; p\right)=\mu(p)\left[p \bar{T} s^{i}+L-G^{i}\right],
$$

for $i=1,2, j \neq i$. To close the model, we assume that settlement involves an even split of the current surplus or equivalently requires $v^{i}-u^{i}=v^{j}-u^{j}{ }^{23}$ Since $s^{i}+s^{j}=1$ and $q^{i}+q^{j}=1$, we can write group $i$ 's one-period payoff under settlement using equations (8) and (13) as follows:

$$
v^{i}=u^{i}\left(G^{i}, G^{j} ; p\right)+\frac{1}{2} S
$$

for $i=1,2, j \neq i$ where $S$ denotes the one-period surplus and is given by

$$
S=\sum_{i=1,2}\left[v^{i}-u^{i}\right]=(1-\phi) \mu(p)[p \bar{T}+\bar{L}-\bar{G}] \geq 0,
$$

which is strictly positive for $\phi<1$. Not surprisingly, the surplus is increasing in the degree of destruction $(1-\phi)$ and decreasing in the allocation of labor to guns production. ${ }^{24}$ Note that the one-period payoff shown in equation (14), in contrast to that under open conflict

\footnotetext{
${ }^{23}$ Alternatively, one might suppose that settlement involves an even split of the current and present discounted value of future surpluses. See McBride and Skaperdas (2014) for such an analysis in a different context. Our focus on an even split of the current surplus only keeps the analysis tractable, though it likely induces a slight bias in the overall preference for fighting. Also, see Anbarci et al. (2002) for an analysis of alternative bargaining norms in a one-period setting.

${ }^{24}$ Of course, it is possible that one group, say group 1 , has some bargaining advantage in the negotiation stage (given $G^{1}$ and $G^{2}$ ), in which case it would get a larger share, $\lambda>\frac{1}{2}$ of the surplus $S$, leaving the remaining, smaller share $1-\lambda$ for the other group. However, we abstract from that possibility here.
} 
shown in equation (8), is not subject to uncertainty. ${ }^{25}$

The implied rule of division is given by

$$
s^{i}=s\left(G^{i}, G^{j} ; p\right)=\phi q\left(G^{i}, G^{j}\right)+(1-\phi) \frac{1}{2}\left[1+\frac{G^{i}-G^{j}}{p \bar{T}}\right],
$$

for $i=1,2, j \neq i$. This rule is a weighted average of two components. The first component is the share of the contested land if it were divided solely on the basis of the groups' winning probabilities. The second component is simply one-half adjusted by the groups' relative guns. The weights depend on the destruction parameter, $1-\phi$. If fighting were to destroy all of the nation's land and labor $(\phi=0)$, land would be divided solely according to this second component. In this extreme case, if the two groups brought identical amounts of guns to the negotiation table, then the contested land would be evenly split; but, if group $i$ were to bring relatively more guns, it would receive a relatively larger share. ${ }^{26}$ In the other extreme case where fighting destroys no resources $(\phi=1)$, the contested land is divided solely on the basis of the groups' winning probabilities given their gun choices.

Due to the static nature of the one-period game under settlement, the expected future one-period payoff functions under settlement will be identical across time and equal to the current one-period payoff function. Letting $G^{i \prime}$ for $i=1,2$ denote group $i$ 's future optimizing allocation of the labor endowment to guns and assuming as before that the future price relative price of oil is equal to the current price, the expected discounted payoffs under settlement, which we denote by $v^{i}$, can thus be written as

$$
V^{i}\left(G^{i}, G^{j}\right)=v^{i}\left(G^{i}, G^{j} ; p\right)+\Delta v^{i}\left(G^{i \prime}, G^{j \prime} ; p\right)
$$

Observe group $i$ 's current guns choice under settlement, in contrast to the case of open conflict, affects only its current payoff. Thus, the incentive to arm in the current period in anticipation of settlement is generally less than the incentive to arm in anticipation of open conflict.

To proceed, differentiate (16) or equivalently (14) with respect to $G^{i}$, given $G^{j}$ and $p$ :

$$
\frac{\partial V^{i}}{\partial G^{i}}=\frac{\partial v^{i}}{\partial G^{i}}=\mu(p)\left[p \bar{T} q_{G^{i}}^{i} \phi-\frac{1}{2}(1+\phi)\right]
$$

for $i=1,2, j \neq i$. The terms inside the square brackets represent together the net marginal benefit of the group's allocation of labor to arming under settlement, measured in units of

\footnotetext{
${ }^{25}$ Of course, if our specification for preferences means that uncertainty is not a central here. If preferences exhibited risk aversion, then the surplus $S$ would necessarily include some compensation for settlement's effect to make the outcome a certain one, in contrast to open conflict, as in Anbarci et al. (2002).

${ }^{26}$ Note that our analysis to follow rules out this extreme case, assuming $\phi>0$. But, if $\phi=0$, neither group would have an incentive to arm.
} 
butter. An increase in guns by group $i$, given $G^{j}$, implies an increase in that group's current share of the disputed land according to the rule of division (15) as determined by the conflict technology $q^{i}$ and a decrease in labor remaining to produce butter, both weighted by $\phi$, as in the case of conflict. In the case of settlement, however, there is an additional cost in terms of a marginal reduction in the available surplus $S$ shown in equation (14b). That added marginal cost is reflected in the term $\frac{1}{2}$. Together with the absence of any future marginal benefit of current arming, this added cost implies that each group has a smaller incentive to arm under settlement than under open conflict, given the opponent's arming choice and the price.

As in the case of open conflict, the specification of the conflict technology in equation (2) implies that the amount of arming by both groups will be strictly positive under settlement. Hence, the expression in equation (17), when evaluated at the optimizing choices of arms anticipating settlement, will be non-negative. Furthermore, depending on $p$, the labor constraint in the production of arms could be binding, as in the case of conflict. Taking this possibility into account while recalling $q_{G^{i}}^{i}=G^{j} / \bar{G}^{2}$, one can show that, in a symmetric equilibrium under settlement, group $i$ 's arming choice is given by

$$
G^{i s}=G^{s}= \begin{cases}\frac{p \bar{T}}{4}\left[\frac{2 \phi}{1+\phi}\right]=L \frac{p}{\pi^{s}} & \text { if } p \leq \pi^{s} \\ L & \text { otherwise }\end{cases}
$$

for $i=1,2$, where $\pi^{s} \equiv\left(\frac{1+\phi}{2 \phi}\right) 2 \bar{L} / \bar{T}$ denotes the threshold value of the price above which the labor constraint in the production of arms binds under settlement. Since arming is identical across the two groups, we have $q^{i}=s^{i}=\frac{1}{2}$ for $i=1,2$. Observe that, similar to the case of open conflict, this allocation of labor is increasing in the relative price of oil provided that the labor constraint is not binding (i.e., $p<\pi^{s}$ ). However, in contrast to arming under open conflict, $G^{s}$ is independent of $\Delta$ and is decreasing in the degree of destruction $(1-\phi)$ for $p \leq \pi^{s}$.

Perhaps more importantly and as anticipated earlier, a comparison of the solution for $G^{s}$ in equation (18) with the solution for $G^{c}$ in equation (11) shows that arming under open conflict is at least as large as that under settlement: $G^{c} \geq G^{s}$ for any $p$. More precisely, note that the binding labor constraint price under conflict $\pi^{c}$ can be no greater than that under settlement $\pi^{s}: \pi^{c}<\pi^{s}$ for $(\Delta, \phi) \in[0, \infty) \times(0,1] \backslash\{(0,1)\}$ and $\pi^{c}=\pi^{s}=2 \bar{L} / \bar{T}$ for $\Delta=0$ and $\phi=1$. In the special case where $\Delta=0$ and $\phi=1, G^{c}=G^{s}$ for all $p$. But, if either $\Delta>0$ or $\phi<1$, then $G^{c}>G^{s}$ for all $p<\pi^{s}$ and $G^{c}=G^{s}$ for all $p \geq \pi^{s}$.

By virtue of the stationarity of this problem mentioned above, the solution for guns under settlement shown in equation (18) applies to all future periods assuming settlement: $G^{i \prime}=G^{s}$ for $i=1,2$. Thus, the groups' equilibrium lifetime payoffs when they settle peacefully under 
free trade are identical.

$$
V \equiv V\left(G^{s}, G^{s}\right)=\mu(p)\left[(1+\Delta)\left(L-G^{s}+\frac{1}{2} p \bar{T}\right)\right]
$$

for $i=1,2$ and all $p$, where $G^{s}$ is as shown in equation (18).

\section{Equilibrium Payoffs and Welfare Implications}

We now examine more carefully the equilibrium payoffs assuming conflict and the equilibrium payoffs assuming settlement, based on the payoff functions in (12) and (19) with their respective equilibrium solutions for arming (11) and (18). Although a central objective of this paper is to understand the groups' incentives to settle their domestic dispute given the firststage choice of guns in the initial period, here we characterize the equilibrium payoffs under settlement and conflict when evaluated at their respective arming solutions. Such a characterization allows us to explore the welfare consequences of the conflict/settlement choice, assuming that they are possible equilibria. To be sure, open conflict is always a subgame perfect, Nash equilibrium. If either group chooses to fight in the second stage, then open conflict necessarily emerges. Anticipating that outcome and given the opponent's choice of $G^{j}=G^{c}$, neither group has an incentive to choose any other level of arms but $G^{i}=G^{c}$. In the section that follows this one, we characterize the conditions under which peaceful settlement is another possible subgame perfect, Nash equilibrium.

To proceed, it is useful to define $\pi^{0} \equiv 2 \bar{L} / \bar{T}$ as the common threshold value of the price under conflict and settlement (respectively, $\pi^{c}$ and $\pi^{s}$ ) in the special, benchmark case where $\delta=\Delta=0$ and $\phi=1$ that implies $G^{c}=G^{s}=L$. Using this definition, we can rewrite those binding labor constraint prices for all feasible values of $\Delta \in[0, \infty)$ and $\phi \in[0,1]$ respectively as $\pi^{c}=\pi^{0}\left(\frac{\phi}{\phi+\Delta}\right)$ and $\pi^{s}=\pi^{0}\left(\frac{1+\phi}{2 \phi}\right)$. Note that $\pi^{c}<\pi^{0}$ for $\Delta>0$ and $\pi^{s}>\pi^{0}$ for $\phi<1$.

\subsection{Equilibrium Payoffs under Settlement}

For this part of the analysis, we start with the case of settlement, as this case is simpler to analyze by virtue of its stationarity. With the definitions of $\pi^{0}$ and $\pi^{s}$ above and equation (18), we can rewrite the equilibrium lifetime payoffs under settlement (19) as follows:

$$
V= \begin{cases}V_{1} \equiv \mu(p) L(1+\Delta)\left[1+\frac{2 p}{\pi^{0}(1+\phi)}\right] & \text { if } \quad p \leq \pi^{s} \\ V_{2} \equiv \mu(p) L(1+\Delta)\left(\frac{2 p}{\pi^{0}}\right) & \text { if } \quad p>\pi^{s}\end{cases}
$$

where as previously defined $\pi^{s}=\pi^{0}\left(\frac{1+\phi}{2 \phi}\right)$. Equation (20) shows that the equilibrium payoff under settlement consists of two segments, $V_{1}$ in the case that the labor constraint in the production of arms is not binding (i.e., for $p \leq \pi^{s}$ ) and $V_{2}$ in the case that it does bind (i.e., for 
$\left.p>\pi^{s}\right)$. Recalling that $\mu(p)=\beta^{\beta}(\alpha / p)^{\alpha}$, one can easily verify that, ignoring the constraint $p<p^{s}, V_{1}$ is strictly quasi-convex in $p$, reaching a unique minimum at $\arg \min _{p} V_{1}=\frac{\alpha(1+\phi)}{2 \beta} \pi^{0}$. In addition, $V_{2}$ is increasing in $p$ for $p \geq \pi^{s}$. As such, the payoff $V$ is strictly quasi-convex in $p$, with a unique minimum at

$$
\pi_{\min }^{s}=\min \left[\frac{\alpha(1+\phi)}{2 \beta} \pi^{0}, \frac{1+\phi}{2 \phi} \pi^{0}\right] .
$$

That unique value depends on the value of $\phi$ relative to $\beta / \alpha$. In particular, when $\phi \leq \beta / \alpha$, we have $\pi_{\text {min }}^{s}=\frac{\alpha(1+\phi)}{2 \beta} \pi^{0}$, the minimum that corresponds to $\arg \min _{p} V_{1}$. Alternatively, when $\phi>\beta / \alpha$, we have $\pi_{\min }^{s}=\frac{1+\phi}{2 \phi} \pi^{0} \equiv \pi^{s}$, the critical value of the price at which the payoff function switches from $V_{1}$ to the second segment, $V_{2}$. Since $\phi \leq 1$, this minimum can obtain only when $\alpha \geq \frac{1}{2}$ or equivalently when oil is valued by relatively more than butter. But, when $\alpha<\frac{1}{2}, \pi_{\min }^{s}$ always corresponds to the minimum of $V_{1}$.

As one can easily verify using equations (7) and (18), the relative price of oil that eliminates trade (which coincides, by symmetry, with the market-clearing price under autarky) is $p_{A}^{s}=\frac{\alpha(1+\phi)}{2(\beta+\phi)} \pi^{0}$. A direct comparison of this price to $\pi_{\min }^{s}$ reveals that $p_{A}^{s}<\pi_{\min }^{s}$. Thus, similar to the finding in Garfinkel et al. (2008), each group's payoff under settlement is minimized at a relative price that exceeds the country's autarky price; for $p$ close to but above $p_{A}^{s}$ so that the country exports oil, the gains from trade are positive but are dominated by the losses due to arming; and increases in $p$ further reduce each group's payoff relative to that under autarky provided initially $p<\pi_{\min }^{s}{ }^{27}$ However, with increases in the relative price above $\pi_{\min }^{s}\left(>p_{A}^{s}\right)$, the payoff under settlement rises. When $\pi_{\min }^{s}<\pi^{s}$, this positive effect emerges since, although the increase in $p$ induces more arming, the implied increase in the costs of insecurity are swamped by the increase in the gains from trade; further increases in $p$ above $\pi^{s}$ accelerate this positive effect on $V$, because the binding labor resource constraint makes arming and thus the costs of insecurity independent of the price, leaving only the additional gains from trade. This effect is similarly at play when $\pi_{\min }^{s}=\pi^{s}$ and $p$ rises above $\pi^{s}$.

The dependence of $V$ on the relative price of oil is shown in Fig. 1 for various values of the other parameters of interest. To start, consider the role of the shadow of the future, $\Delta$. Since $G^{s}$ does not depend on $\Delta$ and increases in $\Delta$ raise the present value of future payoffs,

\footnotetext{
${ }^{27}$ To be more precise, when $p=p_{A}^{s}$, the payoffs to each group under settlement and trade are identical to those under settlement and autarky. As $p$ rises above the autarky price, the gains from trade increase, but these gains are swamped by the increased costs of insecurity. Note also, for $p<p_{A}^{s}$, the payoffs to each group under trade and settlement are greater than those under autarky and settlement, due to the gains from trade and lower costs of insecurity. But, an increase in $p\left(<p_{A}^{s}\right)$ implies lower gains from trade and higher costs of insecurity. While Garfinkel et al. (2008) focus on conflict, the results are similar to what we find here in the case of settlement. This similarity is expected, since the case of conflict in that analysis abstracts from destruction, and as such is analytically equivalent to the limiting case of settlement in the present analysis when $\phi=1$ (i.e., $s^{i}=q^{i}$ ).
} 
we have $\partial V / \partial \Delta>0$ for any price. The independence of arming incentives on $\Delta$ implies further that $\pi^{s}$ remains unchanged with changes in $\Delta$. Nor does $\Delta$ influence $\pi_{\min }^{s}{ }^{28}$ These observations are captured in Fig. 1, by the upward shift in each family of curves (that vary with $\phi)$ as $\Delta$ rises from zero to some positive level. Specifically, given $\phi$ an increase in $\Delta$ implies an increase in $V$, without affecting the critical points, $\pi^{s}$ and $\pi_{\min }^{s}$.

The impact of an increase in the rate of destruction (i.e., a decrease in $\phi$ ) on $V$ is complicated by its effects on both $G^{s}$ and $\pi^{s}$. A reduction in $\phi$ causes $V_{1}$ to rise as it induces less arming by both groups in the current and all future periods for $p<\pi^{s}: \partial V_{1} / \partial(-\phi)>0$. However, for $p>\pi^{s}$, arming is constrained, and that makes $V_{2}$ invariant to changes in $\phi$. Thus, for a given $\Delta$, a reduction in $\phi$ causes $V_{1}$ to shift up and as a result $\pi^{s}$ to rise, as shown in Fig. 1. Notice the non-monotonic dependence of $\pi_{\min }^{s}$ on $\phi$.

\subsection{Equilibrium Payoffs under Open Conflict}

Next consider the case when open conflict is anticipated. Using the definitions of $\pi^{0}$ and $\pi^{c}$ and equation (11), the expected equilibrium lifetime payoff for each group under open conflict in equation (12) can be rewritten as

$$
U= \begin{cases}U_{1} \equiv \mu(p) L(\phi+\Delta)\left[1+\frac{p}{\pi^{0}}\right] & \text { if } p \leq \pi^{c} \\ U_{2} \equiv \mu(p) L\left[\phi \frac{2 p}{\pi^{0}}+\Delta\left(1+\frac{2 p}{\pi^{0}}\right)\right] & \text { if } p>\pi^{c}\end{cases}
$$

where $\pi^{c}=\pi^{0}\left(\frac{\phi}{\phi+\Delta}\right)$ as previously defined. Like the equilibrium payoff under settlement, the expected equilibrium payoff under open conflict consists of two parts. $U_{1}$ is relevant when the labor constraint is not binding in the production of arms, $p \leq \pi^{c}$; and $U_{2}$ is relevant when that constraint is binding, $p>\pi^{c}$.

To explore the dependence of $U$ on the relative price of oil $p$ and the other parameters, it is useful to consider these two components separately. A notable difference between the payoffs under conflict and under settlement arises due to the fact that $U_{2}$ (in contrast to $V_{2}$ ) need not be strictly increasing in $p$. More specifically, for values of $p$ in the neighborhood of $\pi^{c}$, increases in $p$ could cause $U_{2}$ to fall: $\partial U_{2} /\left.\partial p\right|_{p=\pi^{c}}<0$. The reason for this possibility is fairly simple. The cost of arming to a group is invariant to changes in the relative price of oil when for $\pi>\pi^{c}: G^{c}=L$. Therefore, the effect of a change in $p$ in the neighborhood of $\pi^{c}$ on the group's expected payoff would be due solely to terms-of-trade changes both in the current and future periods. The sign of such changes depends on whether the group expects to be a net exporter or a net importer of oil. Our focus here on the case where $G^{c}=L$ implies that each group will necessarily be a exporter of oil in the current period since there is no current

\footnotetext{
${ }^{28}$ Note that $\pi_{\min }^{s}=\pi^{s}$ for $\phi=1$ and $\phi=\phi^{\prime}<1$, but for the highest rate of destruction $\left(\phi=\phi^{\prime \prime}<\phi^{\prime}\right)$, $\pi_{\min }^{s}<\pi^{s}$. These latter points are indicated in the figure by the dot on the (highest) of the two families of payoff functions corresponding to $\Delta=0$ and $\Delta>0$.
} 
production of butter. But, with no arming in future periods (whether the group wins or loses the current-period conflict), each group could very well expect to be a net importer of oil in the future. In this case, an increase in $p$ will improve each group's current terms of trade (implying a positive effect on the current component its expected lifetime payoff), but the increase in $p$ will also worsen its future terms of trade (thus lowering the future component of its expected lifetime payoff). ${ }^{29}$ If the rate of destruction is relatively high (small $\phi$ ) and the shadow of the future is also relatively strong, the net effect on welfare could very well be negative.

The possibility that $U_{2}$ can fall as $p$ rises for $p$ initially close to $\pi^{c}$ complicates matters a little. To proceed, recall that $\mu(p)=\beta^{\beta}(\alpha / p)^{\alpha}$. Thus, as one can easily verify, $U_{1}$ (without the restriction that $p \leq \pi^{c}$ ) is strictly quasi-convex in $p$, reaching a unique minimum at $\pi_{\text {min }}^{c 1}=\frac{\alpha}{\beta} \pi^{0}$. By the same token, $U_{2}$ (similarly without the restriction that $p>\pi^{c}$, but assuming $\left.G^{c}=L\right)$ is strictly quasi-convex in $p$, reaching a unique minimum at $\pi_{\min }^{c 2}=$ $\frac{\alpha}{2 \beta} \pi^{0}\left[\frac{\Delta}{\phi+\Delta}\right]<\pi_{\min }^{c 1} \cdot 30$ Building on these findings, one can show that $U$ is strictly quasiconvex in $p$ reaching a unique minimum at $\pi_{\min }^{c}$, where

$$
\pi_{\min }^{c}=\left\{\begin{array}{ccc}
\pi_{\min }^{c 1} & \text { if } & \pi^{c} \geq \pi_{\min }^{c 1} \\
\pi^{c} & \text { if } & \pi_{\min }^{c 1}>\pi^{c}>\pi_{\min }^{c 2} \\
\pi_{\min }^{c 2} & \text { if } & \pi_{\min }^{c 2} \geq \pi^{c} .
\end{array} \longrightarrow \pi_{\min }^{c}=\left\{\begin{array}{ccc}
\pi_{\min }^{c 1} & \text { if } & \frac{\phi}{\phi+\Delta} \geq \frac{\alpha}{\beta} \\
\pi^{c} & \text { if } & \frac{\alpha}{\beta}>\frac{\phi}{\phi+\Delta}>\frac{\alpha}{2 \beta}\left[\frac{\Delta}{\phi+\Delta}\right] \\
\pi_{\min }^{c 2} & \text { if } & \frac{\alpha}{2 \beta}\left[\frac{\Delta}{\phi+\Delta}\right] \geq \frac{\phi}{\phi+\Delta} .
\end{array}\right.\right.
$$

While the dependence of $\pi_{\min }^{c}$ on the parameters $\alpha / \beta, \Delta$ and $\phi$ is complex, the important point here is that the minimum of $U$ is unique. ${ }^{31}$

Fig. 2 illustrates the dependence of $U$ on the relative price of oil $p$ under alternative values for $\Delta$ and $\phi$. Each panel assumes, for clarity, that $\pi_{\min }^{c}=\pi^{c}$. Consider first the influence of $\Delta$ on $U$. Inspection of (21) readily reveals that $\partial U / \partial \Delta>0$ for all $p$; therefore, the larger the shadow of the future, the higher is the expected payoff under conflict. When there is slack in the resource constraint for arming initially, an increase in $\Delta$ generates two effects on the representative group's payoff: a positive direct effect that raises the current value of future payoffs and a negative indirect effect due to the implied increase in arming by both groups, $G^{c}$. However, the direct effect dominates as $\partial U_{1} / \partial \Delta>0$ holds unambiguously. When the resource constraint on arming binds, the indirect effect vanishes and we are thus left with the direct positive effect, $\partial U_{2} / \partial \Delta>0$. Thus, as shown in Fig. 2a, $U$ shifts upwards as the future's salience increases. Notice that, with this upward shift, the threshold value

\footnotetext{
${ }^{29}$ The market clearing price under autarky and conflict in every future period (with no arming) is $p_{A}^{n}=\frac{\alpha}{2 \beta} \pi^{0}$. Thus, a group's future payoff will fall as $p\left(>\pi^{c}\right)$ rises if $p<p_{A}^{n}$ initially.

${ }^{30}$ As expected, $\pi_{\min }^{c 2}<p_{A}^{n}\left(=\frac{\alpha}{2 \beta} \pi^{0}\right)$.

${ }^{31}$ One special case merits some emphasis. In particular, suppose that $\delta=\Delta=0$ and $\phi \in(0,1]$. Then, $\alpha>\frac{1}{2}$ implies $\pi_{\min }^{c}=\pi^{c}$. By contrast, if $\alpha \leq \frac{1}{2}$, then $\pi_{\min }^{c}=\pi_{\min }^{c 1}$.
} 
of the price above which the labor constraint binds $\left(\pi^{c}\right)$ increases, in contrast to the case of settlement, because the increase in $\Delta$ augments the incentive to arm only under conflict.

Next, consider the importance of the rate of destruction. From equation (21), one can easily confirm that a decrease in $\phi$ reduces payoffs under open conflict: $\partial U / \partial(-\phi)<0$. When the labor constraint is not binding, there are two reinforcing effects. First, greater destruction of open conflict, given arming, directly lowers expected current payoffs. Second, an increase in destruction increases arming incentives in the current period and thus indirectly lowers expected current payoffs. When the labor constraint binds, the negative indirect effect vanishes, but the direct negative effect remains. Notice especially that the overall impact of a decrease in $\phi$ on $U$ contrasts sharply with its impact on $V$ (i.e., $\partial V / \partial(-\phi)>0$, due solely to the indirect effect on arming under settlement, $\left.\partial G^{s} / \partial(-\phi)<0\right)$. Fig. $2 \mathrm{~b}$ illustrates the shifts in the representative group's payoffs caused by increases in the rate of destruction, for $\Delta=0$, which implies that $\pi_{\text {min }}^{c}$ is invariant to changes in $\phi$.

\subsection{A Welfare Comparison of Settlement and Conflict}

We now ask how expected lifetime payoffs under settlement compare with those under open conflict as they both depend on the relative price of oil, the shadow of the future and the rate of destruction caused by open conflict. Recall that arming incentives are at least as large under conflict as they are under settlement: $G^{c} \geq G^{s}$ and $\pi^{c} \leq \pi^{s}$ for all parameter values and $p$. Of course if the labor constraint binds in the production of guns under both conflict and settlement (i.e., when $p \geq \pi^{s}$ ), we have $G^{c}=G^{s}$. However, $G^{c}=G^{s}$ also holds true when the groups attach no value to the future and, at the same time, there is no destruction under conflict (i.e., when $\Delta=0$ and $\phi=1$ ). In this case, as pointed out earlier, $\pi^{s}=\pi^{c}=\pi^{0}$. Accordingly, there is no essential distinction between conflict and settlement when $\Delta=0$ and $\phi=1$, so that $V=U$ for all $p$. This special case serves as a useful benchmark. In all other cases with $p<\pi^{s}$, there is relatively less arming under settlement $\left(G^{s}<G^{c}\right)$ and, moreover, the labor constraint in the production of guns binds at a lower price under conflict than it does under settlement $\left(\pi^{c}<\pi^{s}\right)$.

Subtracting (19) from (12) and then simplifying the resulting expression gives

$$
V-U=\mu(p)\left[\phi G^{c}+(1-\phi) L\left(1+\frac{2 p}{\pi^{0}}\right)-G^{s}(1+\Delta)\right] .
$$

Equation (22) shows that the payoff under settlement relative to that under conflict depends on the relative quantity of arms produced under these two methods of conflict resolution appropriately discounted over the infinite time horizon and the gross amount of labor and land not destroyed when the groups both choose settlement over open conflict.

To develop some valuable intuition, we start by asking how payoffs would compare if there 
were no destruction (and thus no surplus) but the groups attached some value to the future (i.e., $\phi=1$ and $\Delta>0$ ). One can verify that $\pi^{c}=\frac{\pi^{0}}{1+\Delta}<\pi^{0}=\pi^{s}$ in this case. Applying these observations to equation (22), along with the solutions for arming under settlement and conflict respectively shown in equations (18) and (11), gives

$$
\begin{aligned}
\left.(V-U)\right|_{\phi=1} & =\mu(p)\left[G^{c}-G^{s}(1+\Delta)\right] \\
& = \begin{cases}0 & \text { for } p \leq \pi^{c} \\
-\mu(p) L\left[p-\pi^{c}\right] \frac{(1+\Delta)}{\pi^{0}} & \text { for } \pi^{c}<p<\pi^{s} \\
-\mu(p) L \Delta & \text { for } \pi^{s} \leq p .\end{cases}
\end{aligned}
$$

As the expression above shows, the possibility that the labor constraint binds in the production of arms under the two methods of conflict resolution influences the ranking of settlement and conflict in a non-trivial way: $\left.(V-U)\right|_{\phi=1}=0$ for $p \leq \pi^{c}$, whereas $\left.(V-U)\right|_{\phi=1}<0$ for $p>\pi^{c}$. The intuition is as follows. The assumption of no destruction $(\phi=1)$ implies no (gross) land and labor surplus to share under settlement, leaving only the difference in the welfare costs of arming. Under conflict, this cost is the reduction of income in the current period appropriately adjusted by the marginal utility of income, which is just $\mu(p) G^{c}$. Under settlement, this cost is the present value of expending $G^{s}$ in the current and future periods again appropriately adjusted by the marginal utility of income, which is just $\mu(p) G^{s}(1+\Delta)$. As one can easily confirm, for all $p \leq \pi^{c}$ when $\phi=1, G^{c}=(1+\Delta) G^{s}$, implying no difference in payoffs under conflict and settlement. However, when $p$ increases entering the $\left(\pi^{c}, \pi^{s}\right)$ price interval, $G^{s}$ increases while $G^{c}=L$ remains unchanged, implying that the payoff under settlement falls relative to that under conflict, $V<U$. When $p \geq \pi^{s}$ the resource constraint becomes binding under settlement for every period. Thus, although $G^{s}=G^{c}=L$ in the current period so that current welfare costs from arming are identical under conflict and settlement, there is no arming under conflict in future periods, implying again that $V<U$.

We now consider the welfare implications of increasing the rate of destruction (given $\Delta>0$ ) with the help of Fig. 3. This figure assumes that $\Delta>0$ and shows the payoffs that arise under conflict and settlement for several values of $\phi$, including the case of no destruction $(\phi=1)$. The payoff functions associated with $\phi=1$, depicted by the solid curves $V$ and $U$ in the figure, illustrate our results above that $V=U$ for $p \leq \pi^{c}$, whereas $V<U$ for $p>\pi^{c}$. Now let us consider a small increase in the rate of destruction (a fall in $\phi$ from 1 to $\phi^{\prime}$ ). From our earlier discussion, we know that the fall in $\phi$ will cause $V$ to rise and $U$ to fall. The resulting payoffs are depicted in the figure as $V^{\prime}(>V)$ and $U^{\prime}(<U)$, which intersect at points $B$ and $C$. Denote the prices associated with these points by $\underline{\pi}(\phi, \Delta)$ and $\bar{\pi}(\phi, \Delta)$, 
respectively. With some tedious algebra, one can confirm,

$$
\begin{aligned}
\underline{\pi}(\phi, \Delta) & =\frac{(1+\phi) \pi^{0}}{2[-1+\phi(1+\phi+\Delta)]} \\
\bar{\pi}(\phi, \Delta) & =\frac{\Delta \pi^{0}}{2(1-\phi)}
\end{aligned}
$$

When $p \in[\underline{\pi}, \bar{\pi}]$, open conflict weakly dominates settlement; and, when $p \notin[\underline{\pi}, \bar{\pi}]$, settlement strictly dominates open conflict. Additional reductions in $\phi$ (for example, from $\phi^{\prime}$ to $\phi^{\prime \prime}$ ) shift payoffs under settlement up (to $V^{\prime \prime}>V^{\prime}$ ) and shift payoffs under conflict down (to $U^{\prime \prime}<U^{\prime}$ ), thus causing $\underline{\pi}$ to rise and $\bar{\pi}$ to fall until these two prices converge to $\underline{\pi}(\widehat{\phi}, \Delta)=\bar{\pi}(\widehat{\phi}, \Delta)=$ $\pi^{s}(\widehat{\phi}(\Delta))$, depicted by point $E$ in Fig. 3, at a unique $\widehat{\phi}(\Delta) \in(0,1)$, which is given by

$$
\widehat{\phi}(\Delta)=\frac{1}{2}\left[\sqrt{4+\Delta^{2}}-\Delta\right] .
$$

Combining equations (24) and (25), we have

$$
\underline{\pi}(\widehat{\phi}(\Delta), \Delta)=\bar{\pi}(\widehat{\phi}(\Delta), \Delta)=\pi^{s}(\widehat{\phi}(\Delta))=\frac{\Delta \pi^{0}}{2+\Delta-\sqrt{4+\Delta^{2}}}
$$

Building on the results above, we have

Proposition 1 (Payoffs under Conflict and Settlement). For any $\Delta \in[0, \infty)$, there exists a threshold rate of destruction $\widehat{\phi}(\Delta)$ that is decreasing in $\Delta$ and satisfies $\widehat{\phi}(0)=1$ and $\lim _{\Delta \rightarrow \infty} \widehat{\phi}=0$. The payoff functions under conflict and settlement, each evaluated at their respective arming solutions, can be compared as functions of $p$, $\phi$ and $\Delta$ :

(a) If $\Delta=0$ and $\phi=1$, then $U(p, \phi, \Delta)=V(p, \phi, \Delta)$ for all $p>0$.

(b) If $\Delta>0$ and $\phi=1$, then

○ $U(p, \phi, \Delta)=V(p, \phi, \Delta)$ for all $p \leq \pi^{c}$, and

$\circ U(p, \phi, \Delta)>V(p, \phi, \Delta)$ for all $p>\pi^{c}$.

(c) If $\Delta>0$ and $\phi \in[\widehat{\phi}(\Delta), 1)$, then there exist two critical values of the price, $\underline{\pi}(\phi, \Delta)$ that is increasing in $\phi$ and $\bar{\pi}(\phi, \Delta)$ that is decreasing in $\phi$ with $\underline{\pi}(\phi, \Delta) \leq \bar{\pi}(\phi, \Delta)$, such that

$\circ U(p, \phi, \Delta) \geq V(p, \phi, \Delta)$ for $p \in[\underline{\pi}, \bar{\pi}]$ (with equality at $\underline{\pi}$ and $\bar{\pi}$ ); and

○ $U(p, \phi, \Delta)<V(p, \phi, \Delta)$ for $p \in(0, \underline{\pi}) \cup(\bar{\pi}, \infty)$.

(d) If $\Delta>0$ and $\phi \in(0, \widehat{\phi}(\Delta))$, then $U(p, \phi, \Delta)<V(p, \phi, \Delta)$ for all $p>0$.

(e) As $\Delta$ increases, the range of possible values of $\phi$ that imply $V(p, \phi, \Delta)>U(p, \phi, \Delta)$ for all $p$ (part d) shrinks, and the set of prices that imply $V(p, \phi, \Delta)>U(p, \phi, \Delta)$ when $\phi \geq \widehat{\phi}(\Delta)$ (part c) also shrinks. 
This proposition shows the intuitive roles played by the rate of destruction $(1-\phi)$ and the shadow of the future $(\Delta)$ in the ranking of payoffs as has been established in the previous literature (e.g., McBride and Skaperdas, 2007, 2014), but also shows how this intuition is conditioned on trade or more precisely world prices. To start, part (a) focuses on our benchmark case where no value is attached to future single-period payoffs and open conflict is not destructive $(\Delta=0$ and $\phi=1)$. Since the resource allocations are identical under settlement and conflict, these two methods of conflict resolution yield identical expected lifetime payoffs. Building on that benchmark case, part (b) isolates the significance of the shadow of the future for our welfare comparisons, showing that when there is no destruction, a larger shadow of the future tilts the balance in favor of conflict for sufficiently high prices that imply the resource constraint in the production of arms binds under conflict and thus induce specialization in the production of oil for the winning group. Parts (a) and (b) taken together confirm our intuition, that as long as there is no destruction and thus no surplus to split, conflict weakly Pareto dominates settlement for all prices.

Parts (c), (d) and (e) neatly characterize the circumstances under which one method of conflict resolution Pareto dominates the other in payoffs depending on the relative price of oil, the rate of destruction for $\phi<1$, and the shadow of the future for $\Delta>0$. For given $\Delta>0$, decreases in $\phi$ below 1 reduce and eventually eliminate (for $\phi \leq \widehat{\phi}(\Delta)$ ) the range of prices under which conflict generates a strictly higher payoff than settlement, $(\underline{\pi}(\phi, \Delta), \bar{\pi}(\phi, \Delta))$. Thus, as stated in part (d) of the proposition, settlement strictly Pareto dominates conflict for all prices if the rate of destruction is sufficiently high (i.e., $\phi<\widehat{\phi}(\Delta)$. But, as stated in part (c), even when $\phi \geq \widehat{\phi}(\Delta)$, settlement Pareto dominates conflict at sufficiently low and sufficiently high prices, precisely when we expect the gains from trade to be very high. ${ }^{32}$ To gain some intuition for this result, observe that as $p$ approaches zero, arming under both conflict and settlement approach zero, implying that the only difference in payoffs is due to the strictly positive surplus enjoyed by the two groups under settlement, but not under conflict. Conversely, as $p$ approaches $\infty$, the constraint on labor binds under both conflict and settlement so that $G^{c}=G^{s}=L$. Although the costs of insecurity are repeatedly incurred in the future under settlement but not under conflict, the value of the labor savings realized under conflict in terms of butter goes to zero. Finally, part (e) points out, consistent with our intuition, that increases in the strength of the shadow of the future, given some destruction $(\phi<1)$, tend to increase the relative ex ante appeal of conflict.

\section{$5 \quad$ When Is Settlement Feasible?}

The results of the previous section indicate that peaceful settlement could Pareto dominate conflict as it allows the groups to divide the disputed land without incurring the destructive

\footnotetext{
${ }^{32}$ Note especially, $\lim _{p \rightarrow 0} U / V=\lim _{p \rightarrow \infty} U / V=\frac{\phi+\Delta}{1+\Delta}<1$ for all $\phi \in(0,1)$.
} 
effects of conflict. Clearly, an increase in the rate of destruction (all else the same) tends to increase settlement's relative appeal. However, this benefit is not sufficient to predict the emergence of settlement, particularly when the dispute over land is ongoing and the shadow of the future is large. Indeed, as argued above, conflict is always a subgame perfect, Nash equilibrium.

Our primary objective in this section is to characterize the conditions that ensure settlement is another possible subgame perfect, Nash equilibrium. One might naturally approach this problem by examining the groups' second-stage choice of whether to settle peacefully or to declare war given the choice of guns in the initial stage by comparing $V(G, G)$ with $U(G, G)$. Of course, a necessary condition for settlement to possibly emerge in equilibrium is that $V(G, G)>U(G, G)$ when evaluated at the arming choices made in the first stage in anticipation of settlement in the second stage, $G=G^{s}$. However, this condition is not sufficient. In particular, even if $V\left(G^{s}, G^{s}\right)>U\left(G^{s}, G^{s}\right)$ holds, each group $i$ could have an incentive to deviate unilaterally from settlement given the opponent's choice $G^{j}=G^{s}(j \neq i)$, by choosing in the first stage another level of arms, denoted by $G^{i}=G^{d}$, and then choosing open conflict in the second stage, such that $U\left(G^{d}, G^{s}\right)>V\left(G^{s}, G^{s}\right) .{ }^{33}$ The necessary and sufficient condition for settlement to be another possible subgame perfect, Nash equilibrium is that such unilateral deviations are not profitable-i.e., $U\left(G^{d}, G^{s}\right)<V\left(G^{s}, G^{s}\right)$

\subsection{Optimizing Deviations and Expected Payoffs}

To proceed, let $B^{c}\left(G^{j}\right)$ denote group $i$ 's best-response function in anticipation of choosing conflict in the subsequent stage, given its opponent produces $G^{j}$ guns. It is easy to verify that

$$
B^{c}\left(G^{j}\right)=\min \left[\max \left(2 \sqrt{\frac{p}{\pi^{c}} L G^{j}}-G^{j}, 0\right), L\right] \text { for } G^{j}>0
$$

where $\pi^{c}=\frac{\phi}{\phi+\Delta} \pi^{0}$ denotes the threshold value of the relative price of oil above which group $i$ 's labor constraint binds when both groups arm in anticipation of open conflict. Obviously, the analogous critical value under the deviation depends on $G^{j}$. But, we are interested in studying deviation incentives when $G^{j}=G^{s}$. As such, our analysis to follow is based on the best-response function when evaluated at $G^{j}=G^{s}$.

\footnotetext{
${ }^{33}$ That is to say, since this latter sort of deviation for either group $i$ involves both a choice of open conflict in the second stage and an optimizing departure from the arming solution under settlement $G^{d}$ in the first stage, given the opponent's choice of $G^{j}=G^{s}$, it necessarily yields a (weakly) higher payoff than the former deviation that involves only choosing conflict over settlement given $G^{i}=G^{j}=G^{s}: U\left(G^{d}, G^{s}\right) \geq U\left(G^{s}, G^{s}\right)$. Only in the special case where the resource constraint binds in the production of guns under the deviation and under settlement (so that $G^{d}=G^{s}=L$ ) are the two deviations identical, yielding identical payoffs.
} 
Letting $\pi^{d}$ denote the relevant critical value of the price under the deviation, we have

$$
G^{d} \equiv B^{c}\left(G^{s}\right)=\left\{\begin{array}{ccc}
L \frac{p}{\pi^{d}} & \text { for } & p \leq \pi^{d} \\
L & \text { for } & p>\pi^{d}
\end{array}\right.
$$

where $\pi^{d}=\frac{\pi^{s}}{2 \sqrt{\pi^{s} / \pi^{c}}-1}$ and, as previously defined, $\pi^{s}=\frac{1+\phi}{2 \phi} \pi^{0}$. Note that in our benchmark case where $\Delta=0$ and $\phi=1$, all of the critical values of the price converge to the same value: $\pi^{c}=\pi^{d}=\pi^{s}=\pi^{0}$. More generally, when $\Delta>0$ and $\phi<1, \pi^{c}<\pi^{d}<\pi^{s}$ holds. Thus, we have $G^{d} \in\left[G^{s}, G^{c}\right]$. To be more precise, observe the following rankings of arming along with the implied values of $q^{i}\left(G^{d}, G^{s}\right)$ from equations (2), (18), and (26), as they depend on the prevailing relative price of oil:

(i) $p \in\left(0, \pi^{d}\right) \Rightarrow G^{s}<G^{d}<G^{c} \leq L \Rightarrow q^{i}=\frac{\pi^{s}}{\pi^{s}+\pi^{d}}$;

(ii) $p \in\left(\pi^{d}, \pi^{s}\right) \Rightarrow G^{s}<G^{d}=G^{c}=L \Rightarrow q^{i}=\frac{\pi^{s}}{\pi^{s}+p}$; and,

(iii) $p \in\left(\pi^{s}, \infty\right) \Rightarrow G^{s}=G^{d}=G^{c}=L \Rightarrow q^{i}=\frac{1}{2}$.

Then, with the solution for $G^{d}$ in equation (26) and the expected payoff function under conflict (9), one can derive the expected lifetime payoff to group $i$ that unilaterally deviates from $G^{i}=G^{s}$ in the first stage and chooses conflict in the second, which we denote by $W \equiv U\left(G^{d}, G^{s}\right)$ :

$$
W= \begin{cases}W_{1}=\mu(p) L(\phi+\Delta)\left[1+\frac{p}{\pi^{0}}\left(\frac{\pi^{c}}{\pi^{d}} \frac{\pi^{s}}{\pi^{d}}\right)\right] & \text { for } p \leq \pi^{d} \\ W_{2}=\mu(p) L\left[\Delta+4 \phi \frac{p / \pi^{c}}{1+p / \pi^{s}}\right] & \text { for } \pi^{d}<p<\pi^{s} \\ W_{3}=\mu(p) L\left[\Delta+2 \phi \frac{p}{\pi^{c}}\right] & \text { for } \pi^{s} \leq p .\end{cases}
$$

Thus, the expected lifetime payoff obtained by a group that optimally deviates from the settlement outcome consists of three segments depending on the relative price of oil.

\subsection{A Comparison of Payoffs under the Optimizing Deviation and Settlement}

The necessary and sufficient condition for peaceful settlement to be a subgame perfect, Nash equilibrium is that $V \equiv V\left(G^{s}, G^{s}\right) \geq U\left(G^{d}, G^{s}\right) \equiv W$. To analyze this condition, we first return to our benchmark case, where groups attach no value to the future and conflict is non-destructive (i.e., $\Delta=0$ and $\phi=1$ ). In this case, since $\pi^{c}=\pi^{d}=\pi^{s}=\pi^{0}$, there are only two distinct segments for $W$-namely, $W_{1}$ and $W_{3}$ corresponding respectively to when $p<\pi^{s}$ and $p \geq \pi^{s}$. What is more, since there are no differences in the allocation of resources under conflict and settlement in this benchmark case, we have $W=U=V$ for all $p>0$.

Next, suppose that the groups attach some value to the future, but continue to suppose that conflict is non-destructive (i.e., $\Delta \in(0, \infty)$ and $\phi=1)$. One can confirm, using equations 
(27) and (21), that $W>U$ for all $p \in\left(0, \pi^{s}\right)$ whereas $W=U$ for all $p \in\left[\pi^{s}, \infty\right)$. Then, from Proposition 1(b), keeping in mind that $\pi^{c}<\pi^{s}$, we have that $W>V$ for all $p>0$. Even though $U=V$ for $p<\pi^{c}$ when there is no destruction and the groups value the future, each group has a strictly positive incentive to deviate unilaterally from the settlement outcome. Hence, in this case, conflict is the unique subgame perfect, Nash equilibrium.

But, what happens when conflict is destructive $(\phi<1)$ ? Inspection of $(27)$ reveals that the dependence of $W$ on the relative price of oil is non-monotonic. Note especially that, depending on the values of $\Delta$ and $\phi, W$ need not be quasi-convex in $p$ for $p \in\left(\pi^{d}, \pi^{s}\right)$. Thus, precisely characterizing the relationship between $W$ and $V$ for alternative values of prices, discount factors and rates of destruction is quite complicated.

To begin our analysis, we define $D \equiv W / V$ as the relative profitability for group $i$ to deviate from the settlement outcome:

$$
D \equiv \frac{W}{V}= \begin{cases}D_{1}=\frac{\phi+\Delta}{1+\Delta}\left[\frac{1+\frac{p}{\pi^{0}}\left(\frac{\pi^{c} \pi^{s}}{\pi^{d} \pi^{d}}\right)}{1+\frac{p}{\phi \pi^{s}}}\right] & \text { for } p \leq \pi^{d} \\ D_{2}=\frac{\Delta+\frac{4 p \phi}{\pi^{c}\left(1+\frac{p}{\pi^{s}}\right)}}{(1+\Delta)\left(1+\frac{p}{\phi \pi^{s}}\right)} & \text { for } \pi^{d}<p<\pi^{s} \\ D_{3}=\frac{\phi+\Delta}{1+\Delta}+\frac{\pi^{0} \Delta}{2 p(1+\Delta)} & \text { for } \pi^{s} \leq p .\end{cases}
$$

The following lemma identifies several interesting benchmark results that help develop some intuition:

Lemma 1 Suppose $\Delta \in(0, \infty)$ and $\phi \in(0,1)$. Then,

(a) $\lim _{p \rightarrow 0} W(p, \phi, \Delta)=\lim _{p \rightarrow 0} U(p, \phi, \Delta)$.

(b) $W(p, \phi, \Delta) \geq U(p, \phi, \Delta)$ for all $p$ and with equality for $p \geq \pi^{s}$.

(c) $\lim _{p \rightarrow 0} D(p, \phi, \Delta)=\lim _{p \rightarrow \infty} D(p, \phi, \Delta)=\frac{\phi+\Delta}{1+\Delta}<1$.

(d) $\lim _{p \rightarrow \pi_{-}^{s}} \frac{\partial D}{\partial p}<0$ and $\lim _{p \rightarrow \pi_{+}^{s}} \frac{\partial D}{\partial p}<0$.

(e) $D\left(\pi^{s}, \phi, \Delta\right) \gtreqless 1$ if $\phi \gtreqless \widehat{\phi}(\Delta)$.

Part (a) follows readily from equations (21) and (27). This result makes sense, because as $p$ goes to zero, arming under conflict, settlement and the deviation converge to zero. Since both conflict and the deviation imply identical security costs as well as identical probabilities (equal to $\frac{1}{2}$ ) of taking full control of the disputed land ( $\phi \bar{T}$ in the initial period and $\bar{T}$ in all future periods), the payoffs must be the same.

Part (b), which similarly follows from equations (21) and (27), also makes sense. When $p \geq \pi^{s}$, the labor constraint is binding not only under the optimizing deviation but also when both groups expect either settlement or conflict and arm accordingly. Thus, arming and thus 
the security costs under the deviation and under conflict are identical: $G^{s}=B^{c}\left(G^{s}\right)=G^{d}=$ $G^{c}=L$. Furthermore, the probability of winning the dispute over land under the deviation and conflict are the same and equal to $\frac{1}{2}$. As such, they yield equal identical expected lifetime payoffs. When $p<\pi^{s}$, the labor constraint does not bind under settlement, implying that the optimal deviation involves security costs that are no greater than those under conflict: $G^{s}<B^{c}\left(G^{s}\right)=G^{d} \leq G^{c}$. But, whether $G^{d}<G^{c}$ or $G^{d}=G^{c}$, the optimal deviation gives a strictly greater probability of taking full control over the disputed land than that under conflict $\left(q\left(G^{d}, G^{s}\right)>q\left(G^{c}, G^{c}\right)=\frac{1}{2}\right)$, thereby yielding strictly higher expected payoffs.

Part (c) follows from parts (a) and (b) and our earlier comparison of conflict and settlement payoffs when prices take on extreme values. ${ }^{34}$ Thus, when prices are very low or very high, settlement dominates conflict and, moreover, there exist no incentives to deviate from settlement. However, because there exists a range of prices under which optimal deviations yield higher expected payoffs relative to conflict (specifically, $W>U$ for $p \in\left(0, \pi^{s}\right)$ as pointed out in part (b)), settlement could fail to be a stable equilibrium for (at least) some prices values under which settlement Pareto dominate open conflict $(V>U)$.

This possibility reveals itself a little more clearly with the next two parts of Lemma 1. Although one can see from (28) that, in general, $D$ is non-monotonic in $p$, part (d) states that $D$ is decreasing in $p$ for prices in the neighborhood of $\pi^{s} \cdot{ }^{35}$ Moreover, part (e) indicates that $W$ exceeds or falls short of $V$ at $\pi^{s}$ depending on whether $\phi$ is greater than or less than $\widehat{\phi}(\Delta)$, shown in equation (25). ${ }^{36}$ Now suppose $\phi=\widehat{\phi}(\Delta)$. Fig. 4 shows the implied $V$ and $U$ curves which, for reasons argued earlier, meet each other at point $B$ where $p=\pi^{s}(\widehat{\phi}(\Delta))$. Thus, as shown in the figure, $V \geq U$ holds for all $p>0$ and as an equality for $p=\pi^{s}(\widehat{\phi}(\Delta))$. Furthermore, as shown in the figure, $W=V$ at $p=\pi^{s}$ (as implied by part (e) of the lemma). Then, parts (c) and (d), suggest that there exists at least one price $\underline{\underline{\pi}} \in\left(0, \pi^{s}\right)$ such that $D>1$ for all $p \in\left(\underline{\underline{\pi}}, \pi^{s}\right) .37$ This implication is illustrated in Fig 4 , showing that, for the range of prices associated with interval $A B$, the optimal deviation is profitable. Thus, even though settlement weakly dominates conflict in this case (i.e., $\phi=\widehat{\phi}(\Delta)$ ), there exists a range of prices that precludes settlement from being a stable equilibrium.

\footnotetext{
${ }^{34}$ See especially footnote 32 .

${ }^{35}$ Straightforward differentiation of (28) reveals that

$$
\lim _{p \rightarrow \pi_{-}^{s}} \frac{\partial D}{\partial p}=-\frac{\phi\left[\pi^{c} \Delta+\pi^{s}(1-\phi) \phi\right]}{\pi^{c} \pi^{s}(1+\Delta)(1+\phi)^{2}} \text { and } \lim _{p \rightarrow \pi_{+}^{s}} \frac{\partial D}{\partial p}=-\frac{\pi^{0} \Delta}{2(p)^{2}(1+\Delta)} .
$$

${ }^{36}$ This follows from the fact that

$$
\left.D\right|_{p=\pi^{s}}=\frac{\phi+\Delta}{1+\Delta}+\frac{\phi \Delta}{(1+\phi)(1+\Delta)} \text {. }
$$

${ }^{37}$ Note that Fig. 4 is drawn under the assumption that $\pi_{\min }^{s}=\arg \min _{p} V_{1}<\pi^{s}$. However, this assumption is not necessary for the result in view of part (d) of the lemma.
} 
The above raises the question of whether there exists a threshold level of $\phi(<\widehat{\phi}(\Delta))$, such that $V>W$ for all $p>0$ if $\phi$ is below that threshold. The answer to this question depends on the value of $\Delta$ as stated in the following proposition:

Proposition 2 (Payoffs under the Optimal Deviation and Settlement). There exists a critical value of $\Delta$, denoted by $\widetilde{\Delta}$, such that if $\Delta \in(0, \widetilde{\Delta})$, then there exists a threshold value of $\phi, \widetilde{\phi}(\Delta)<\widehat{\phi}(\Delta)$, that divides the parameter space as follows:

(a) If $\phi \in[\widetilde{\phi}(\Delta), 1)$, then there exist two critical values of the price, $\underline{\underline{\pi}}(\phi, \Delta)$ and $\overline{\bar{\pi}}(\phi, \Delta)$ with $\underline{\underline{\pi}} \leq \overline{\bar{\pi}}$ such that

$\circ W(p, \phi, \Delta) \geq V(p, \phi, \Delta)$ for $p \in[\underline{\underline{\pi}}, \overline{\bar{\pi}}]$ (with equality at $\underline{\underline{\pi}}$ and $\overline{\bar{\pi}}$ ); and

○ $W(p, \phi, \Delta)<V(p, \phi, \Delta)$ for $p \in(\overline{\overline{0}}, \underline{\underline{\pi}}) \cup(\overline{\bar{\pi}}, \infty)$.

(b) If $\phi \in(0, \widetilde{\phi}(\Delta))$, then $W(p, \phi, \Delta)<V(p, \phi, \Delta)$ for all $p>0$.

If $\Delta \in[\widetilde{\Delta}, \infty)$, then there exists no threshold value of $\phi$, such that $\phi$ below that values implies settlement is a stable equilibrium for all $p>0$.

Thus, provided that the groups do not attach too much weight to the future, settlement could be a feasible equilibrium outcome for all $p>0$ when the rate of destruction is not too low (or $\phi$ is not too high). Note that, since $\widetilde{\phi}(\Delta)<\widehat{\phi}(\Delta)$, the condition for settlement to be feasible for all $p>0$ is stronger than the condition for settlement to be Pareto preferred given $\Delta \in(0, \widetilde{\Delta})$. Even when the rate of destruction is too low to ensure that the deviation is not profitable for all $p>0$, settlement could emerge as a stable equilibrium as long as $p$ is sufficiently high or low.

What happens when $\Delta \in[\widetilde{\Delta}, \infty)$ ? Again, it depends on the actual value of $\Delta$. In particular, there exists another critical value for $\Delta, \widetilde{\widetilde{\Delta}}>\widetilde{\Delta}$ giving rise to two additional intervals, $[\widetilde{\Delta}, \widetilde{\widetilde{\Delta}})$, and $[\widetilde{\widetilde{\Delta}}, \infty)$, with the following properties:

(i) If $\Delta \in[\widetilde{\Delta}, \widetilde{\widetilde{\Delta}})$, then there exists a range of moderate values of $\phi$, such that if $\phi$ falls within that range, then $V>W$ for all $p>0$. For extreme values of $\phi, V>W$ holds only for extreme values of $p$.

(ii) If $\Delta \in(\widetilde{\widetilde{\Delta}}, \infty]$, then there exists no value of $\phi$ for which $V>W$ for all $p>0$. For $\Delta$ in this highest range, $V>W$ holds only for extreme values of $p$.

Although it is possible to provide more precise characterization results for each of these two cases, for simplicity here we illustrate what happens in each of the three cases, including the one characterized in Proposition 2, with Fig. 5.

This figure includes three panels, each corresponding to one of the three different ranges of $\Delta$ identified above. We start with low values of $\Delta$-i.e., those in $(0, \widetilde{\Delta})$ - and gradually 
consider higher values. The vertical axis in each panel measures $\phi$, whereas the horizontal axis measures $p$. Each of the curves represents combinations of $\phi$ and $p$, conditioned on $\Delta$, for which $D=W / V=1$.

Consider the middle dashed (pink) curve in panel (a) corresponding to an intermediate value of $\Delta\left(\Delta^{\prime}\right)$ within the relevant range. Now consider the relatively low value of destruction $\left(\phi>\widehat{\phi}\left(\Delta^{\prime}\right)\right)$ corresponding to the (black) horizontal line in the figure. That horizontal line intersects the middle dashed (pink) curve at two points, defining two critical values of the price, $\underset{=}{=}\left(\phi, \Delta^{\prime}\right)$ and $\overline{\bar{\pi}}\left(\phi, \Delta^{\prime}\right)$. In particular, the part of the horizontal line that lies above the curve represents the (moderate) range of prices, $p \in(\underline{\underline{\pi}}, \overline{\bar{\pi}})$, that cannot sustain settlement, whereas the parts of the horizontal line that lie below the curve represent the (extreme) values of the price, $p \in(0, \underline{\underline{\pi}}) \cup(\overline{\bar{\pi}}, \infty)$, that can sustain settlement in equilibrium. As destruction increases ( $\phi$ falls given $\Delta=\Delta^{\prime}$ ), the corresponding price ranges that sustain settlement expand. Note especially the minimum of the dashed (pink) curve, shown at $\phi=\widetilde{\phi}\left(\Delta^{\prime}\right)$. Values of $\phi$ below this minimum (reflecting relatively high rates of destruction) imply settlement is a stable equilibrium for all $p>0$.

Next, consider the lower solid (blue) curve that is associated with a larger (but still relatively small) value of $\Delta$-i.e., $\Delta^{\prime \prime} \in\left(\Delta^{\prime}, \widetilde{\Delta}\right)$. This curve and the price ranges it generates show a certain monotonicity between the range of prices that sustain settlement and $\phi$ and $\Delta$. Specifically, for this slightly higher value of $\Delta$, the union of the sets of prices that sustain settlement is relatively smaller for any given rate of destruction $\phi$, but is once again increasing in the rate of destruction $(1-\phi)$. By the same token, the threshold value of $\phi$ associated $\Delta^{\prime \prime}>\Delta^{\prime}$ is lower than that assuming $\Delta^{\prime}: \widetilde{\phi}\left(\Delta^{\prime \prime}\right)<\widetilde{\phi}\left(\Delta^{\prime}\right)$. Conversely, the smaller is $\Delta$ within the interval under consideration (consider, for example, the highest dotted (green) curve associated with $\Delta<\Delta^{\prime}$ ), the larger are the unions of the two extreme set of prices that render settlement sustainable for any given $\phi>\widetilde{\phi}(\Delta)$ and the larger is the threshold value of $\phi, \widetilde{\phi}(\Delta)$, below which settlement is sustainable for all $p>0$.

Panel (b) shows that matters change considerably for intermediate values of $\Delta \in[\widetilde{\Delta}, \widetilde{\widetilde{\Delta}}]$. Let us start with the two dashed (pink) curves corresponding to $\Delta=\Delta^{\prime}{ }^{38}$ When $\phi$ is relatively high (low), the relevant curve of the two is the U-shaped (inverse U-shaped) one. Now consider the horizontal line drawn in the figure for a relatively high value of $\phi$. Its intersection with a given $\mathrm{U}$-shaped curve pins down the critical values of $p$ (given $\Delta^{\prime}$ ), which define the sets of (extreme) prices that render settlement a possible equilibrium outcome, as well as the set of (moderate) prices that preclude the emergence of settlement as a stable equilibrium.

When we consider very low rates of destruction (high values of $\phi$ ) given the same value of

\footnotetext{
${ }^{38} \mathrm{Keep}$ in mind that the value of $\Delta^{\prime}$ assumed in panel (b) is greater than that for the middle (pink) curve drawn in panel (a).
} 
$\Delta=\Delta^{\prime}$, the intersection of the relevant horizontal and the dashed (pink) inverse U-shaped curve once again gives the critical values of $p$, which define the range of (moderate) prices that preclude settlement from being an equilibrium and the ranges of extreme prices that can support settlement. The key difference here is that higher rates of destruction (or lower values of $\phi$ ) imply not a larger but a smaller union of sets of prices that sustain settlement as an equilibrium. Indeed, there exists a range of intermediate values of destruction $(\phi)$, depending on the value of $\Delta$ within the range under consideration in panel (b), that implies settlement is a stable equilibrium for all possible prices. This range is illustrated in Fig. $5 \mathrm{~b}$ by $\left(\widetilde{\phi}^{2}\left(\Delta^{\prime}\right), \widetilde{\phi}^{1}\left(\Delta^{\prime}\right)\right)$. Even so, the figure shows generally that a smaller shadow of the future $\Delta \in(\widetilde{\Delta}, \widetilde{\widetilde{\Delta}})$ implies a greater set of prices that render settlement a stable equilibrium.

Panel (c), which is based on still larger values of $\Delta, \Delta \in(\widetilde{\widetilde{\Delta}}, \infty)$, can be interpreted similarly. We make two noteworthy observations. First, like the case where $\Delta \in(\widetilde{\Delta}, \widetilde{\widetilde{\Delta}})$ as shown in panel (b), panel (c) indicates that the relationship between $\phi$ and the range of prices that sustain settlement is non-monotonic. In particular, lower rates of destruction (higher $\phi$ ) can induce a smaller set of prices that support settlement as long as the rate of destruction is initially low (consider the higher horizontal line in Fig. 5(c) drawn at a relatively higher value of $\phi$ ). However, when the rate of destruction is initially high (consider the lower horizontal line in Fig. 5(c) drawn at a relatively lower value of $\phi$ ), a lower rate of destruction (an increase in $\phi$ ) can induce a larger range of prices of prices that sustain settlement. Second, panel (c) shows, when the shadow of the future is sufficiently large $(\Delta \in(\widetilde{\widetilde{\Delta}}, \infty))$, there is no longer any value of $\phi$ that implies settlement can emerge as an equilibrium for all possible prices. Nevertheless, even in this case, a smaller shadow of the future implies a larger set of prices that can sustain settlement.

Despite the complexities of our results, one tendency stands out: a larger shadow of the future, all else the same, makes it more likely that conflict will be the unique subgame perfect, Nash equilibrium, even when settlement Pareto dominates conflict. This result contrasts sharply with Folk-theorem type arguments based on repeated static games (e.g., Friedman, 1971), which suggest that a sufficiently large shadow of the future can support cooperation and be welfare-enhancing. However, it is not surprising in the current structurally dynamic setting where fighting today has the long-term benefit of reducing the future need to arm.

One might naturally wonder whether the pattern of trade matters for the determination of whether or not settlement is sustainable in equilibrium. As it turns out, we cannot offer a general answer to that question. However, it is important to observe, from our analysis and discussion revolving around Fig. 5 as well as Lemma 1(c), that settlement is always a possible subgame perfect, Nash equilibrium given there is some destruction associated with open conflict and the relative price of the good produced intensively with the disputed resource (oil) is extremely high or low. For such extreme values of the price of oil, we expect 
the gains from trade to be the highest.

\section{Trade Openness and Equilibrium Payoffs}

Building on our findings above, we now turn to explore how changes in trade costs can influence equilibrium outcomes, depending on the other parameters of interest - most notably, the destructiveness of open conflict $(1-\phi)$. This analysis provides new insights into the link between trade openness and the risk of violent domestic conflict and, more generally, into the possible welfare consequences of increased trade openness in our setting.

\subsection{Prices and Equilibrium Payoffs}

We lay the groundwork for this analysis, by studying the influence of the price of oil $p$ on equilibrium payoffs. Of course, as argued above, open conflict is always a subgame perfect, Nash equilibrium. Furthermore, we have shown that, while there are some circumstances under which open conflict is the only stable equilibrium, there are other circumstances under which settlement is another possible stable equilibrium. In what follows, we suppose that, for parameter values which imply both conflict and settlement are possible stable equilibria, the groups "select" the more efficient of the two. ${ }^{39}$ Taking this perspective, it is obvious from our analysis above that continuous changes in $p$ affect payoffs not only in a continuous manner as they influence the terms of trade and the incentives to arm. They can also affect payoffs in a discontinuous manner, as they can induce a discrete change in the method of conflict resolution, from open conflict to peaceful settlement or vice versa.

Fig. 6 illustrates these effects assuming a relatively small shadow of the future as emphasized in Proposition 2 (i.e., $\Delta \in(0, \widetilde{\Delta})$ ) for various values of $\phi$, the rate of destruction. The dashed (pink) line in each panel shows the payoff under settlement, $V$; the solid (blue) line shows the payoff under open conflict $U$; and, the dotted (green) line shows the hypothetical payoff under the optimizing deviation, $W$. Notice that in each panel, $W=U$ for $p \geq \pi^{s}$ where the labor constraint on the production of arms binds in under settlement, conflict and the deviation. ${ }^{40}$ Most importantly, the thick, solid (red) line in each panel depicts the stable and efficient equilibrium payoff as a function of $p>0$.

Panel (a) illustrates the result stated in Proposition 2(b) that, if destruction is sufficiently high (i.e., $\phi<\widetilde{\phi}(\Delta)<\widehat{\phi}(\Delta)$ ), settlement is feasible as well as Pareto dominant for all $p>0$.

\footnotetext{
${ }^{39}$ Note that this "selection" is consistent with Bernheim et al.'s (1987) refinement of the equilibrium concept of subgame perfection, "perfectly coalition-proof" equilibrium. In particular, when both peaceful settlement and open conflict are subgame perfect, Nash equilibria, both are immune to unilateral deviations. However, when in addition settlement Pareto dominates conflict, conflict is not (whereas settlement is) immune to coalitional deviations.

${ }^{40}$ Observe also in the figure that, as noted earlier, $W$ need not be quasi-convex for $p<\pi^{s}$. The possible non-quasi-convexity of $W$ holds more precisely for $p \in\left(\pi^{d}, \pi^{s}\right)$, but $\pi^{d}$ is not shown in the figure. For now ignore the positioning of $p_{A}^{n}$. That becomes important in our upcoming discussion of trade openness.
} 
As discussed earlier, an increase in $p$ changes the terms of trade, the sign of which depends on where $p$ is in relation to the trade-eliminating price under settlement, $p_{A}^{s}$. In particular, for $p<p_{A}^{s}$ an increase in $p$ implies a deterioration in the terms of trade, whereas for $p \geq p_{A}^{s}$ the terms of trade improves with increases in $p$. However, for all $p \in\left(0, \pi^{s}\right)$ an increase in $p$ increases the incentive to arm in the current and in every future period, thereby implying higher security costs. Thus, as argued earlier in Section 4.1, the equilibrium payoff in this case is strictly quasi-convex in $p$, reaching a minimum at $p=\pi_{\min }^{s}>p_{A}^{s}$ (not shown), where the increase in the gains from trade equals the increase in security costs. But, because $V>W \geq U$ for all $p>0$, there are no discrete changes (jumps or drops) in the equilibrium payoff when $p$ changes continuously.

With a lower rate of destruction, however, matters differ, as shown in panel (b) which assumes $\phi^{\prime} \in(\widetilde{\phi}(\Delta), \widehat{\phi}(\Delta))$. Specifically, from Proposition 2(a), settlement is no longer a stable equilibrium for all $p>0$. An increase in $p$ from an initially low value $\left(<\underline{\underline{\pi}}\left(\phi^{\prime}, \Delta\right)\right)$ causes payoffs to decrease continuously along $V$; but, as $p$ increases beyond $\underline{\underline{\pi}}\left(\phi^{\prime}, \Delta\right)$ (associated with point $A$ in the figure), payoffs drop sharply-precisely where settlement becomes unstable $(W>V)$. The discontinuity in payoffs arises here because the shift from settlement to conflict implies a discrete increase in arming in the current period and the destruction of resources that accompanies open conflict; although the switch from settlement to open conflict also implies an added savings in future resources afforded by resolving the dispute once and for all, this benefit is swamped by the two aforementioned added costs. Further increases in $p$ eventually lead to a jump in equilibrium payoffs at point $B$ (associated with $\left.p=\overline{\bar{\pi}}\left(\phi^{\prime}, \Delta\right)\right)$, where settlement becomes stable again $(V>W)$. At this point, current arming falls discretely and the destruction of resources is avoided; furthermore, this gain more than offsets the higher future costs of arming that accompany settlement but not open conflict. ${ }^{41}$ In any case, from Proposition $1(\mathrm{~d})$ since $\phi^{\prime}<\widehat{\phi}(\Delta)$, settlement Pareto dominates open conflict for all $p>0$. Thus, for intermediate values of the price, $p \in\left(\underline{\underline{\pi}}\left(\phi^{\prime}, \Delta\right), \overline{\bar{\pi}}\left(\phi^{\prime}, \Delta\right)\right)$ such that settlement cannot be supported as an equilibrium outcome, the economy is stuck in the "bad" equilibrium - namely, open conflict.

Finally, panel (c) shows what happens for an even lower rate of destruction, $\phi^{\prime \prime}>\widehat{\phi}(\Delta)$. From Proposition 1(c), such a value of $\phi$ implies there exists an intermediate range of prices for which open conflict Pareto dominates peaceful settlement: $p \in\left(\underline{\pi}\left(\phi^{\prime \prime}, \Delta\right), \bar{\pi}\left(\phi^{\prime \prime}, \Delta\right)\right)$. For all other prices $p \notin\left(\underline{\pi}\left(\phi^{\prime \prime}, \Delta\right), \bar{\pi}\left(\phi^{\prime \prime}, \Delta\right)\right)$, settlement dominates open conflict. Thus, for $p \in\left(\underline{\underline{\pi}}\left(\phi^{\prime \prime}, \Delta\right), \underline{\pi}\left(\phi^{\prime \prime}, \Delta\right)\right)$, the economy is once again stuck in the "bad" equilibrium; however, for $p \in\left(\underline{\pi}\left(\phi^{\prime \prime}, \Delta\right), \overline{\bar{\pi}}\left(\phi^{\prime \prime}, \Delta\right)\right)$, conflict emerges as the stable and Pareto dominant out-

\footnotetext{
${ }^{41}$ Note that, for the parameter values assumed to draw Fig. $6(\mathrm{~b}), \overline{\bar{\pi}}\left(\phi^{\prime}, \Delta\right)<\pi^{s}\left(\phi^{\prime}\right)$, which is what gives rise to the discrete jump in payoffs as $p$ rises above $\overline{\bar{\pi}}\left(\phi^{\prime}, \Delta\right)$. However, it is also possible that $\overline{\bar{\pi}}\left(\phi^{\prime}, \Delta\right)>\pi^{s}\left(\phi^{\prime}\right)$, in which case the transition from conflict to settlement would be "smoother." This alternative possibility, which necessarily arises when $\phi>\widehat{\phi}(\Delta)$ (as argued below), is captured in panel (c) of the figure.
} 
come. It is important to notice the assumption underlying the figure that $\phi^{\prime \prime}>\widehat{\phi}(\Delta)$ implies $\bar{\pi}\left(\phi^{\prime \prime}, \Delta\right)=\overline{\bar{\pi}}\left(\phi^{\prime \prime}, \Delta\right)$, and furthermore that this common value is greater than $\pi^{s}\left(\phi^{\prime \prime}\right)$ as shown in the figure. ${ }^{42}$ Hence, another important difference between panel (c) and panel (b) is that the shift from conflict to settlement at $p=\overline{\bar{\pi}}\left(\phi^{\prime \prime}, \Delta\right)$ does not imply a discontinuous jump in payoffs. Since $\overline{\bar{\pi}}\left(\phi^{\prime \prime}, \Delta\right)>\pi^{s}\left(\phi^{\prime \prime}\right)$, current-period arming under settlement and conflict are identical at $p=\overline{\bar{\pi}}\left(\phi^{\prime \prime}, \Delta\right): G^{s}=G^{c}=L$. The equality of the two payoffs $(V=U)$ at this price, then, reflects the equality of the welfare costs of conflict's destructive effects preempted by settlement in the current period and the welfare gains of the future savings in resources afforded by conflict in the current period. As $p$ rises further, the benefits of avoiding destruction rise above the costs of a repeated diversion of productive resources to arming in the future.

\subsection{Trade Costs and Equilibrium Outcomes}

As emphasized in the empirical literature, conflict can undermine the gains from external trade by disrupting it. As such, the option to participate in world markets implies a higher opportunity cost to fighting (as compared with settling). Although we do not explicitly capture that opportunity cost here, an analysis of trade costs in our setting can shed new light on this issue. Thus, with the groundwork laid out above, we now consider the possible importance of barriers to trade or more precisely exogenous trade costs in influencing the conditions that make settlement a possible equilibrium outcome. ${ }^{43}$ In view of the complexities that arise in characterizing those conditions generally as they depend on $p, \phi$ and $\Delta$, we maintain our focus on the case emphasized in Proposition 2-namely, that the shadow of the future is relatively small: $\Delta \in(0, \widetilde{\Delta})$.

Another potentially complicating factor is that whether the groups enter into open conflict or settle their dispute over land peacefully matters for the pattern of trade given any price. In general and as predicted by the traditional paradigm that abstracts from conflict, the pattern of trade depends on how the relative price of oil compares with the country's autarky price. What differs and complicates our analysis here is that this (domestic) market clearing price itself depends on whether the groups fight or not. As defined earlier, $p_{A}^{s}$ denotes the autarky price when groups settle; $p_{A}^{c}$ denotes the autarky price in the initial period when they fight; and $p_{A}^{n}$ denotes the autarky price in future periods when open conflict breaks out

\footnotetext{
${ }^{42}$ The reasoning is as follows. Recall from equations (24) and (25) that $\bar{\pi}(\phi, \Delta)=\pi^{s}(\phi)$ at $\phi=\widehat{\phi}(\Delta)$, and that an increase in $\phi$ increases $\bar{\pi}(\phi, \Delta)$ and decreases $\pi^{s}(\phi)$. Since by assumption $\phi^{\prime \prime}>\widehat{\phi}(\Delta), \bar{\pi}\left(\phi^{\prime \prime}, \Delta\right)>$ $\pi^{s}\left(\phi^{\prime \prime}\right)$ holds true. Then, Lemma $1(\mathrm{~b})$ implies $W=U$ for $p \geq \bar{\pi}\left(\phi^{\prime \prime}, \Delta\right)>\pi^{s}\left(\phi^{\prime \prime}\right)$. Since $\bar{\pi}\left(\phi^{\prime \prime}, \Delta\right)$ gives the critical value of $p$ above which $V \geq U, \overline{\bar{\pi}}\left(\phi^{\prime \prime}, \Delta\right)$ gives the threshold value of $p$ above which $V \geq W$, and $U=W$, we necessarily have $\bar{\pi}\left(\phi^{\prime \prime}, \bar{\Delta}\right)=\overline{\bar{\pi}}\left(\phi^{\prime \prime}, \Delta\right)>\pi^{s}\left(\phi^{\prime \prime}\right)$.

${ }^{43}$ Of course, a more complete analysis would involve supposing that trade costs increase with the intensity of conflict. We conjecture that incorporating such link would tend to make conflict less appealing, but would leave our finding that conflict can Pareto dominate peaceful settlement intact.
} 
in the initial period.

Using equation (7), along with the solutions for arming in any given period (in the current period under settlement $G^{s}$ shown in equation (18), in the current period under fighting $G^{c}$ shown in equation (11), and in any future period after an initial one with fighting $G=0$ ), we have the following:

$$
\begin{aligned}
p_{A}^{n} & =\frac{\alpha}{2 \beta} \pi^{0} \\
p_{A}^{s} & =\frac{\alpha(1+\phi)}{2[\beta(1+\phi)+\alpha \phi]} \pi^{0}=\frac{\alpha}{2 \beta+\alpha \frac{2 \phi}{1+\phi}} \pi^{0} \\
p_{A}^{c} & =\frac{\alpha}{2 \beta+\alpha\left(1+\frac{\Delta}{\phi}\right)} \pi^{0} .
\end{aligned}
$$

Straightforward comparisons of these autarkic prices reveal that $p_{A}^{c}<p_{A}^{s}<p_{A}^{n}$. Thus, for $p$ initially at some relatively low value $\left(p<p_{A}^{c}\right)$, the country is a net importer of oil regardless of how the dispute over land is resolved. As $p$ enters the $\left(p_{A}^{c}, p_{A}^{s}\right)$ range, the country becomes a net exporter of oil in the current period under conflict, but continues to be a net importer of oil in all future periods; yet for such prices under settlement, the country is a net importer of oil in all periods. Further increases in $p$ above $p_{A}^{s}$ imply that the country under settlement is a net exporter of oil in all periods. Still, for such values of $p<p_{A}^{n}$, the country under conflict continues to be a net importer of oil in all future periods. Finally, for $p>p_{A}^{n}$, the country is always a net exporter of oil. These different possibilities suggest that reversals in trade patterns can emerge as the world price of oil changes. Such reversals can arise simply because the change in price influences the incentive to arm and thus the diversion of labor resources away from the production of butter. However, a change in the price can also induce a discrete change in the equilibrium mode of conflict resolution and that itself can reverse the pattern of trade. In any case, these different possibilities can also complicate our analysis of how trade costs matter.

To abstract from such complications, we suppose that the world price, now denoted by $\pi$, is strictly greater than the autarkic price under no arming, $p_{A}^{n}$, so that under free trade the country is a net exporter of oil whether the groups settle or fight. ${ }^{44}$ Continuing to view $p$ as the internal or domestic price of oil for this country, we also assume that $p>p_{A}^{n}$, so that $p \in\left(p_{A}^{n}, \pi\right)$. Thus, we limit our focus to trade costs that are consistent with a strictly positive net export of oil. Any existing differences between $\pi$ and $p$ reflect exogenous

\footnotetext{
${ }^{44}$ This assumption also rules out another possible complicating factor - namely, that there could be reversals in trade patterns with changes in $p$ (given $\pi$ ) under the (hypothetical) optimizing deviation by one group. It turns out that the autarky price that would emerge if one of the groups were to deviate from settlement, whether or not the labor constraint binds in the production of arms for the deviating group, is always greater than $p_{A}^{c}$ and less than $p_{A}^{s}\left(<p_{A}^{n}\right)$. Thus, limiting our attention to cases where $\pi>p_{A}^{n}$ is sufficient to ensure that each group always expects to be a net exporter of oil.
} 
trade costs of the "iceberg" type that effectively "melt" traded goods in transit. Given these simplifying assumptions implying that the country is always a net exporter of oil, our analysis of the previous subsection can be applied directly to study the importance of trade costs. Specifically, an increase (decrease) in $p$ where initially $p \in\left(p_{A}^{n}, \pi\right)$ implies a decrease (increase) in trade costs.

From Proposition 2(b), it should be clear that decreases in trade costs or equivalently increases in $p$ have no implications for the feasibility of settlement to emerge as an equilibrium outcome when conflict is sufficiently destructive (i.e., $\phi<\widetilde{\phi}(\Delta)$ ). However, observe from Fig. 6(a) that reductions in trade costs do matter for payoffs. In particular, provided $p_{A}^{n}>\pi_{\min }^{s}$, increases in $p$ above $p_{A}^{n}$ cause payoffs to fall initially and then eventually to rise. ${ }^{45}$ Thus, even in the simplest of cases, globalization need not be welfare improving.

Now suppose that $\phi=\phi^{\prime} \in(\widetilde{\phi}(\Delta), \widehat{\phi}(\Delta))$ and reconsider Fig. 6(b). From Propositions 1(d) and 2(a), settlement Pareto dominates open conflict for all $p>0$, but can be supported in equilibrium only for $p \notin\left(\underline{\underline{\pi}}\left(\phi^{\prime}, \Delta\right), \overline{\bar{\pi}}\left(\phi^{\prime}, \Delta\right)\right)$. Assuming that $p_{A}^{n}<\underline{\underline{\pi}}\left(\phi^{\prime}, \Delta\right)$, Fig. 6(b) illustrates the possibility that the transition from high to lower trade costs could initially render peaceful settlement unstable, in which case globalization would lead to a sharp decline in welfare. However, as trade costs continue to fall, welfare rises along the payoff function under conflict, $U$. Assuming, in addition, that the world price is sufficiently high (i.e., $\left.\pi>\overline{\bar{\pi}}\left(\phi^{\prime}, \Delta\right)\right)$, continued reductions in trade costs to zero eventually reestablish settlement as a stable equilibrium and further improve payoffs. This same sort of effect is illustrated in Fig. 6(c), similarly assuming that $\pi>\overline{\bar{\pi}}\left(\phi^{\prime \prime}, \Delta\right) .{ }^{46}$

The different panels in Fig. 6 illustrate that the welfare consequences of increased trade openness, in the form of a decrease in trade costs, are highly conditioned on conflict's destructive effects. ${ }^{47}$ Consistent with the empirical findings of Martin et al. (2008), we find that a decrease in trade costs can induce open conflict and thus be welfare-deteriorating, particularly when conflict's destructive effects are relatively small (panels (b) and (c)); however, depending on the initial degree of trade openness as well as conflict's destructive effects, a decrease in trade costs can also induce a switch from open conflict to settlement.

\footnotetext{
${ }^{45}$ Recall that $\pi_{\min }^{s}=\min \left[\frac{\alpha(1+\phi)}{2 \beta} \pi^{0}, \frac{1+\phi}{2 \phi} \pi^{0}\right]$. Since $p_{A}^{n}<\frac{\alpha(1+\phi)}{2 \beta} \pi^{0}$ holds unambiguously given conflict is not completely destructive $(\phi>0)$, a sufficient condition for a reduction in trade costs to be initially welfarereducing in this exercise is that $p_{A}^{n}<\pi^{s}$ or equivalently that $\alpha$ not be too large $(\alpha<(1+\phi) /(2+\phi))$.

${ }^{46} \mathrm{We}$ could also consider tariffs, but would have to modify the analysis to account for tariff revenues in the determination of national income. Nevertheless, we anticipate that the analysis would not change much. Trade liberalization (a decrease in tariffs), like globalization (a decrease in transportation costs) could enhance or lead to a deterioration of welfare due to its (discrete) effect on the condition for peaceful settlement to be a possible subgame perfect, Nash equilibrium, as well as its effects on arming incentives (and, of course, the standard reduction in deadweight losses).

${ }^{47}$ Though not analyzed here, it should be obvious, from our analysis in Section 5.2 , that the welfare consequences of a decrease in trade costs also depend on the shadow of the future.
} 


\section{Concluding Remarks}

In this paper, we have analyzed open conflict and peaceful settlement, each as a means along with arming for groups within a single nation to "resolve" their dispute over a contested resource (land). Peaceful settlement involves a division of that insecure resource, supported by the arms chosen by the groups before coming to the negotiation table, without having to suffer the sort of destruction that invariably comes with fighting. As others have found in different settings, a higher rate of destruction associated with open conflict, then, tends to make settlement relatively more appealing in an ex ante sense. However, because settlement resolves only the current-period dispute, the groups find themselves in the same dispute in the future and that requires the allocation of future resources to arming. Open conflict, by contrast, is destructive, but it also allows the contending groups to resolve their dispute once and for all, so that no future resources are allocated to arming. Consistent with the findings of others, as the future becomes more salient, the value of this savings increases and the ex ante relative appeal of open conflict tends to rise.

We find that, in addition to conflict's rate of destruction and the strength of the shadow of the future, the world price of the good produced intensively with the disputed resource can matter too, suggesting that trade can play a central role in determining which method of conflict resolution Pareto dominates the other. Interestingly, we find that, all else the same, settlement is most likely to be preferred ex ante precisely under the conditions when the gains from trade are largest - namely, when the price of oil takes on extremely high or low values.

Of course, the condition that ensures the Pareto dominance of peaceful settlement does not ensure that settlement is, in addition to open conflict, a possible subgame perfect, Nash equilibrium. The price of oil, the rate of destruction under conflict and the shadow of the future all matter in determining the profitability of unilateral deviations from settlement; and, as such, these parameters matter in determining whether settlement is possibly another stable equilibrium. We find that the conditions for settlement to be sustained as an equilibrium

outcome are generally stronger and a bit more complex than the conditions for settlement to be Pareto dominant.

Because the analysis is based on a number of simplifying assumptions, one might naturally ask if the results are robust to relaxing them. The assumption that conflict's destructive effects are temporary, for example, tends to make conflict relatively more appealing. But, as noted earlier, assuming instead that these effects are permanent tends to simplify the analysis and sharpen the central results. In particular, we find that the condition for settlement to be a possible stable equilibrium looks more like the condition for settlement to be Pareto dominant, even though stronger, for all possible values of the shadow of the future, not just small values.

Clearly, our assumptions regarding the nature of the strategic advantage conferred on 
the winner of open conflict are strong, and tend to tilt the balance in favor of conflict over settlement. However, these assumptions, too, can be relaxed. One possibility, explored by McBride and Skaperdas (2007), involves assuming that the strategic advantage in future conflict can be realized by a group only after having won a certain number of battles. Another possibility would be to suppose that conflict does not "resolve" the dispute over land once and for all, but only for a finite number of periods. Yet, another approach would be to continue to suppose that open conflict in the first period precludes the possibility of future open conflict and thus future destruction, but also suppose that open conflict calls into play, for all future periods, a different rule of division of the disputed resource, one that requires both groups to arm while giving the victor of the first-period conflict at least some advantage in future disputes. Although any of these alternative, less extreme assumptions would tend to tilt the balance back in favor of peaceful settlement, the central results should not be affected.

The government, though not explicitly modeled here, can play a meaningful role in this setting that could be explored in future research. One extension would involve considering the possibility that the government uses trade policy (either trade liberalization or trade protection) to influence arming incentives as well as the nature of equilibrium. Interestingly, a welfare-minded policymaker could very well opt for policies that result in overt conflict. Conversely, and depending on the environment in which they operate, governments might view trade agreements as commitments that deter internal conflict.

A perhaps more obvious extension would be to consider the government's role in strengthening the institutions of governance and enforcement to enhance the security of claims to the nation's resources. Currently, there are many ongoing civil wars that are costly and rooted in natural resources. ${ }^{48} \mathrm{~A}$ central finding of our analysis is that, in the absence of effective governance and sufficient state capacity, neither a larger shadow of the future nor a more liberal trade regime will necessarily reduce the risk of open conflict. Thus, following McBride et al. (2011) and Garfinkel et al. (2012), one could extend the analysis by supposing the government makes costly long-term investments that render some fraction of the disputed resource secure. We conjecture that, as the fraction of land that is contestable falls, the severity of conflict falls too, and peaceful settlement becomes a more viable method to resolve the (remaining) conflict. However, to the extent that governance and enforcement are imperfect so that some amount of the nation's land remains contestable, open conflict cannot be ruled out as a possible equilibrium.

\footnotetext{
${ }^{48}$ See, for example, Ross (2003).
} 


\section{References}

Anbarci, Nejat, Stergios Skaperdas, and Constantinos Syropoulos (2002). "Comparing Bargaining Solutions in the Shadow of Conflict: How Norms Against Threats Can Have Real Effects," Journal of Economic Theory 106(1): 1-16.

Anderson, James E. and Douglas Marcouiller (2005), "Anarchy and Autarky: Endogenous Predation as a Barrier to Trade," International Economic Review 46(1): 189213.

Barbieri, Katherine and Gerald Schneider (1999). "Globalization and Peace: Assessing New Directions in the Study of Trade and Conflict," Journal of Peace Research 36(4): 387-404.

Bernheim, B. Douglas, Bezalel Peleg, and Michael D. Whinston (1987). "CoalitionProof Nash Equilibria: I. Concepts," Journal of Economic Theory 42(1): 1-12.

Blattman, Christopher and Edward Miguel (2010). "Civil War," Journal of Economic Literature 48(1): 3-57.

Collier, Paul, V.L. Elliott, Havard Hegre, Anke Hoeffler, Marta Reynal-Querol, and Nicholas Sambanis (2003). Breaking the Conflict Trap; Civil War and Development Policy, (World Bank Policy Report), Washington, DC: World Bank and Oxford University Press.

Dal Bó, Ernesto and Pedro Dal Bó (2011). "Workers, Warriors, and Criminals: Social Conflict in General Equilibrium," Journal of the European Economic Association 9(4): $646-77$.

Dixit, Avinash (2004), Lawlessness and Economics: Alternative Models of Governance (Princeton: Princeton University Press).

Dixit, Avinash (2015). "Governance, Trade and Investment," Research in Economics, this issue.

Fearon, James D. (1995). "Rationalist Explanations for War," International Organization 49(3): 379-414.

Friedman, James (1971). "A Non-cooperative Equilibrium for Supergames," Review of Economic Studies 38(1): 1-12.

Garfinkel, Michelle R., Michael McBride and Stergios Skaperdas (2012). "Governance and Norms as Determinants of Arming," Revue d'Economie Politique 122(2): $197-212$. 
Garfinkel, Michelle R. and Stergios Skaperdas (2000). "Conflict without Misperceptions or Incomplete Information: How the Future Matters," Journal of Conflict Resolution 44(6): 793-807.

Garfinkel, Michelle R., Stergios Skaperdas, and Constantinos Syropoulos (2008). "Globalization and Domestic Conflict," Journal of International Economics 76(2): 296308.

Garfinkel, Michelle R., Stergios Skaperdas, and Constantinos Syropoulos (2015). "Trade and Insecure Resources," Journal of International Economics 95(1): 98-114.

Gilpin, Robert (1987). The Political Economy of International Relations, Princeton: Princeton University Press.

Gowa, Joanne (1994). Allies, Adversaries, and International Trade, Princeton: Princeton University Press.

Hirshleifer, Jack (1989). "Conflict and Rent-seeking Success Functions: Ratio vs. Difference Models of Relative Success," Public Choice 63(2): 101-112.

Klare, Michael T. (2001). Resource Wars: The New Landscape of Global Conflict, New York: Henry Holt and Company.

Martin, Philippe, Thierry Mayer, and Mathias Thoenig (2008). "Civil Wars and International Trade," Journal of the European Economics Association 6(2-3): 541-550.

McBride, Michael and Stergios Skaperdas (2007). "Explaining Conflict in Low-Income Countries: Incomplete Contracting in the Shadow of the Future," in M. Gradstein and K.A. Konrad, (eds.), Institutions and Norms in Economic Development Cambridge, MA: MIT Press, 141-161.

McBride, Michael and Stergios Skaperdas (2014). "Conflict, Settlement and the Shadow of the Future," Journal of Economic Behavior and Organization 105: 75-89.

McBride, Michael, Gary Milante and Stergios Skaperdas (2011). "Peace and War with Endogenous State Capacity," Journal of Conflict Resolution 55(3): 446-468.

McBride, Michael, Stergios Skaperdas, and Pi-Han Tsai (2014). "Why Go to Court? Bargaining Failure under the Shadow of Trial with Complete Information," UCI working paper.

Polachek, Solomon W. (1980). "Conflict and Trade," Journal of Conflict Resolution 24(1): $55-78$. 
Powell, Robert (2006). "War as a Commitment Problem," International Organization 60(1): 169-203.

Ross, Michael (2003). "Natural Resource Curse: How Wealth Can Make You Poor," in I. Bannon and P. Collier (eds.), Natural Resources and Violent Conflict: Options and Actions Washington DC: World Bank, 17-42.

Skaperdas, Stergios (1996). "Contest Success Functions," Economic Theory 7(2): 283290.

Skaperdas, Stergios and Constantinos Syropoulos (1996). "Can the Shadow of the Future Harm Cooperation?" Journal of Economic Behavior and Organization 29(3): $355-372$.

Skaperdas, Stergios and Constantinos Syropoulos. (2001). "Guns, Butter, and Openness: On The Relationship Between Security And Trade." American Economic Review, Papers and Proceedings 91(2): 353-357.

Tullock, Gordon (1980). "Efficient Rent Seeking," in J.M. Buchanan, R.D. Tollison and G. Tullock (eds.) Toward a Theory of the Rent Seeking Society College Station: Texas A\&M University Press, 3-15.

Waltz, Kenneth N. (1979). Theory of International Politics, New York: Random House. 


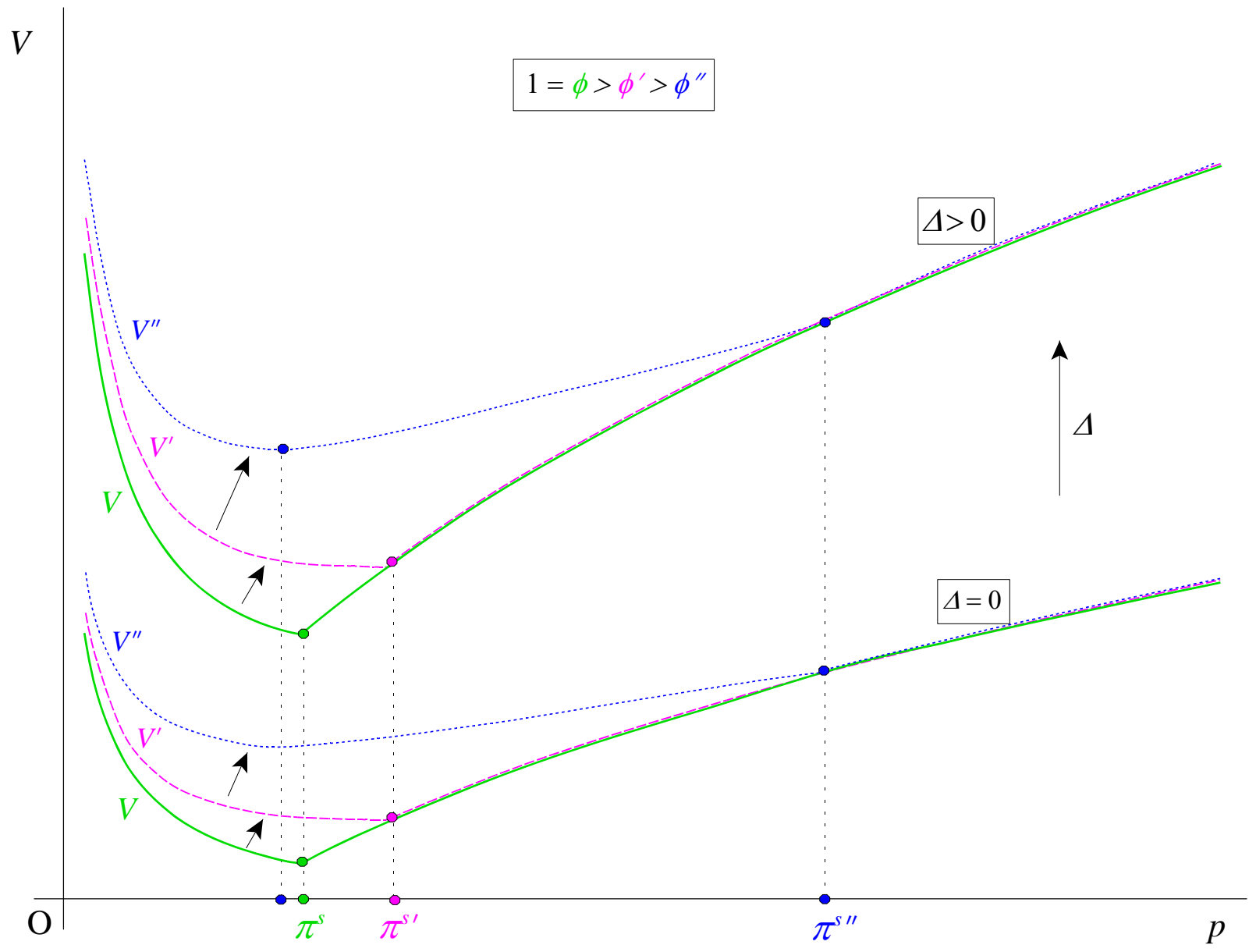

Figure 1: Settlement Payoffs under Alternative Discount Factor Values and Rates of Destruction 


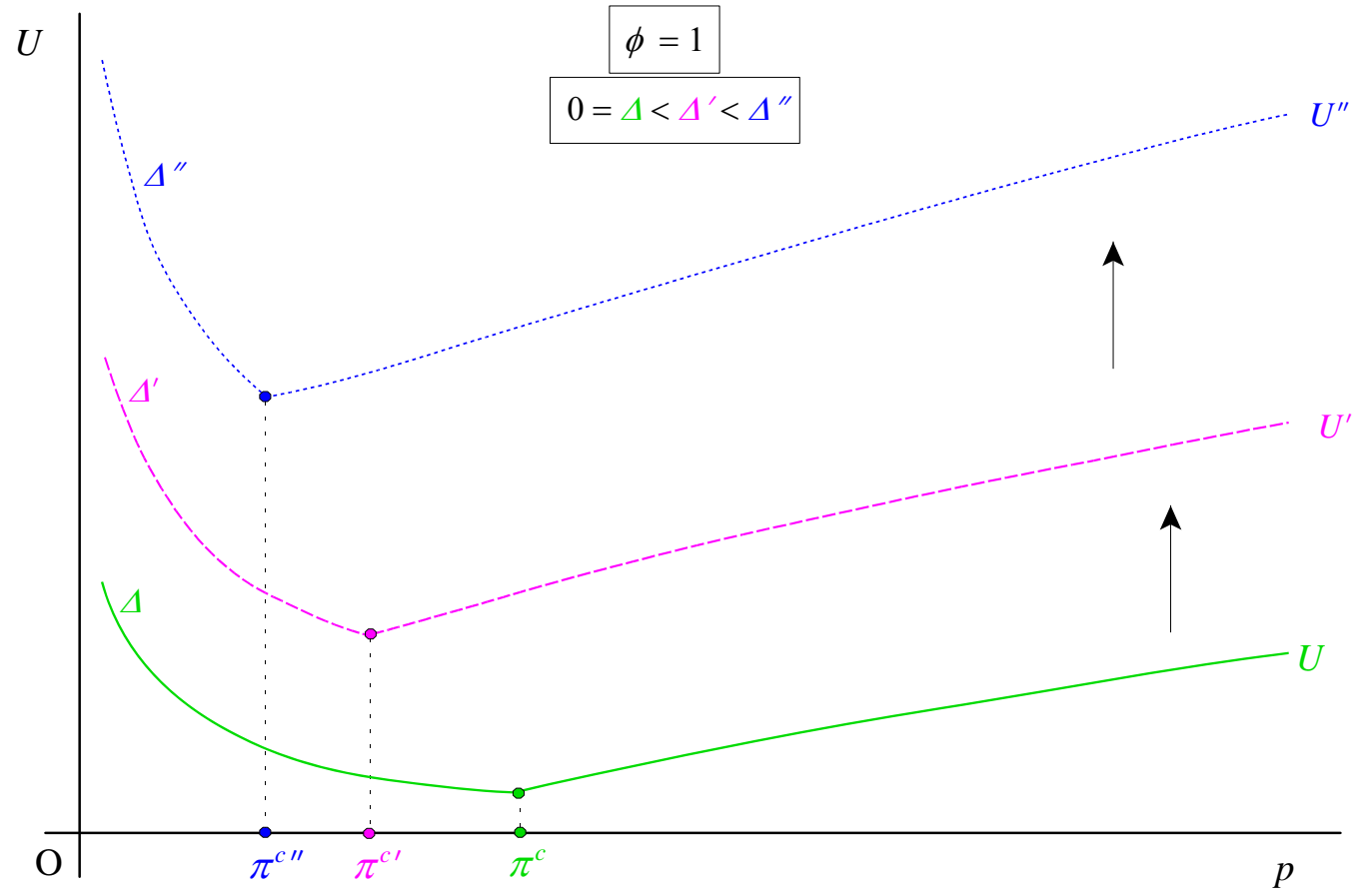

Figure 2a: Conflict Payoffs under Alternative Discount Factor Values

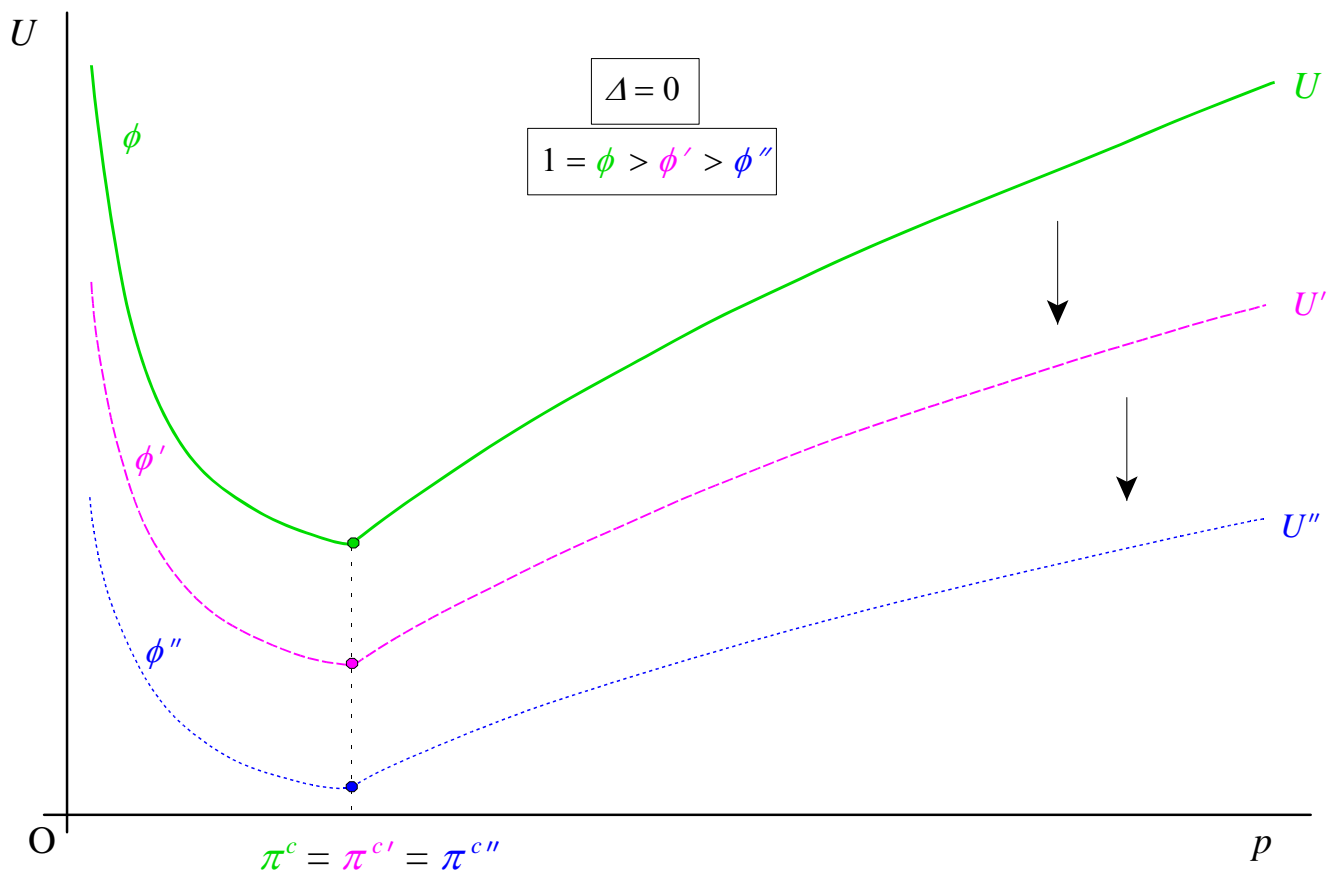

Figure 2b: Conflict Payoffs under Alternative Rates of Destruction 




Figure 3: Conflict and Settlement Payoff Comparisons under Various Rates of Destruction 


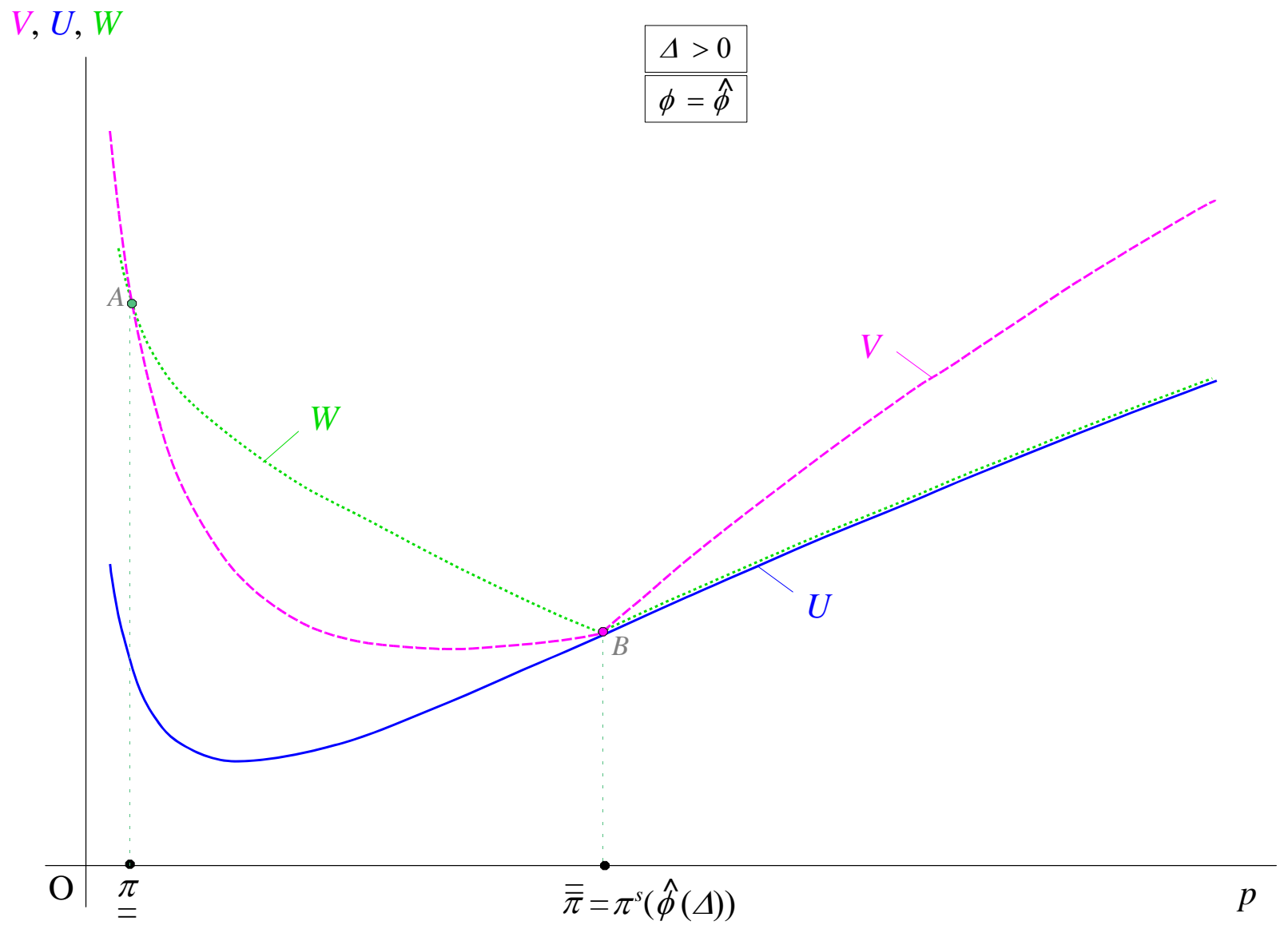

Figure 4: Devation Incentives and Payoff Comparisons 
(a)

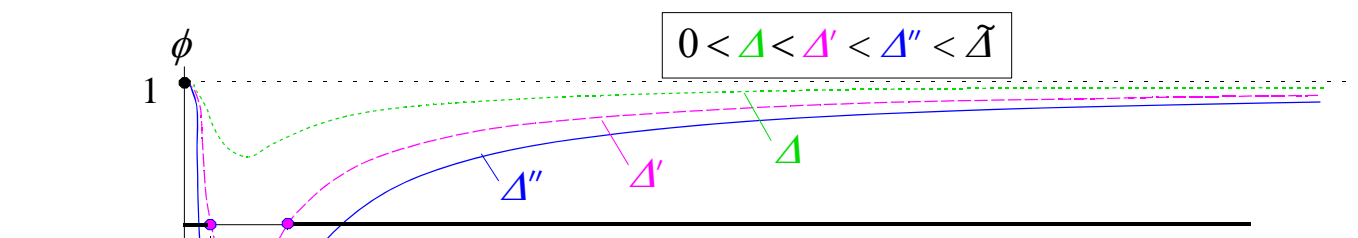

(b)

(c)
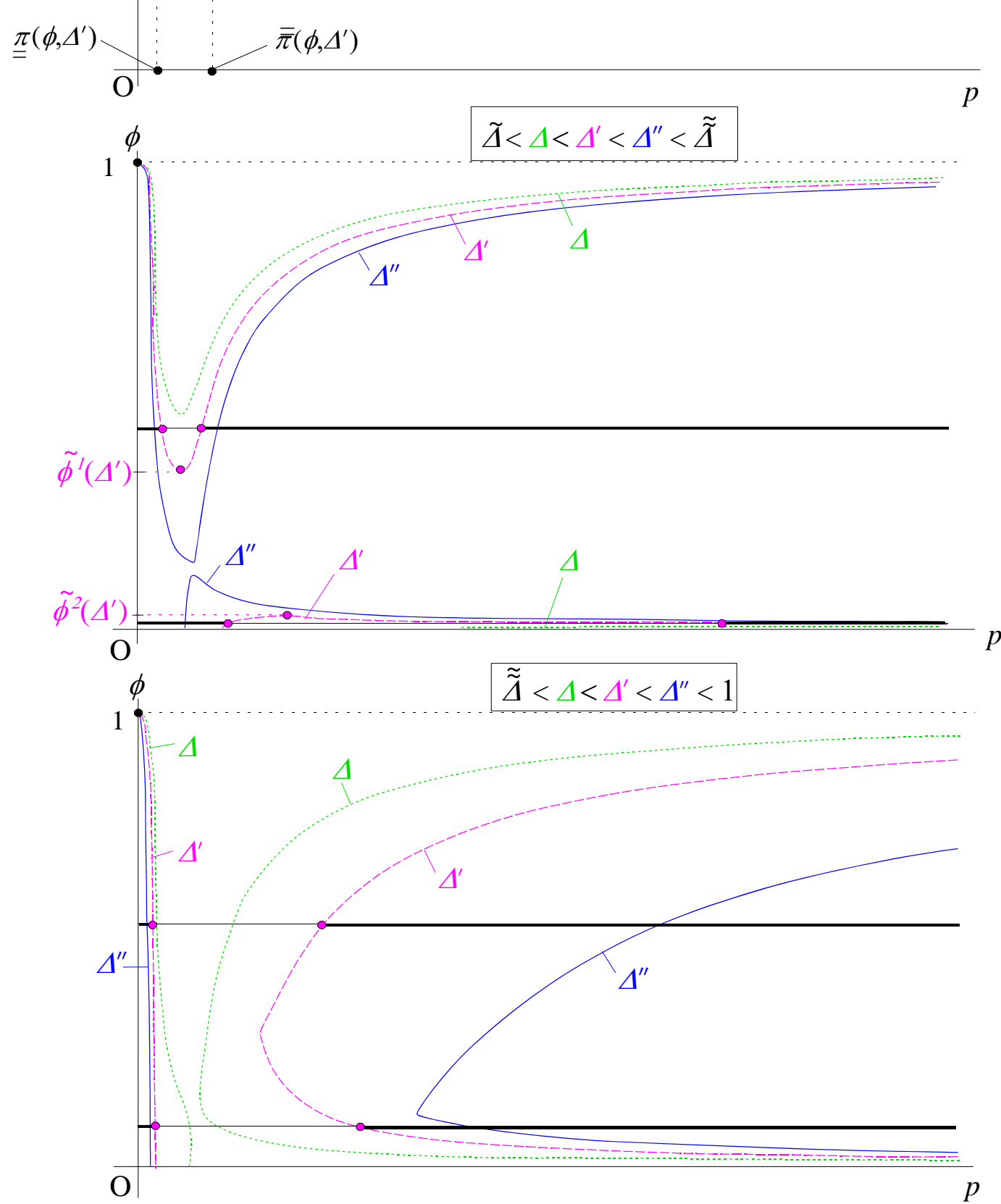

Figure 5: Sets of Parameter Values That Render Settlement a Subgame Perfect Equilibrium 




Figure 6: The Impact of Price Changes on Equilibrium Outcomes and Payoffs 